\title{
Protective Effect Of Oral And Intranasal Bacterial Lysates In Mice
}

\author{
Hanaa, A. Mansour* and Maha G. Soliman** \\ *Pharmacology Department (Medical microbiology and immunology unit), National \\ Organization for Drug Control And Research (NODCAR). \\ **Zoology Department, Faculty of Science ( girls ), Al Azhar University.
}

\begin{abstract}
In this study albino mice were used to test the beneficial effect of bacterial lysates vaccination against lethal dose of Pseudomonas aeroginosa. Escherichia coli lysate, Pseudomonas aeroginosa lysate, Staphylococcus aureus lysate and mixed bacterial lysates were administered through the oral and the intranasal routes, both in the presence and absence of Freund's adjuvant versus a placebo. Pseudomonas aeroginosa fifty percent lethal dose ( LD50) was injected intraperitonealy following intranasal and oral vaccination. The placebo and the four bacterial lysates were also used in association with Freund's adjuvant. The results of the LD50 in intranasal vaccinated groups were $50 \%, 37.5 \%, 100 \%, 0 \%$ and $12.5 \%$, and those with Freund's adjuvant were $25 \%, 25 \%, 12.5 \%, 62.5 \%, 0 \%$ and $0 \%$ respectively. The results of LD50 in oral vaccination were $50 \%, 25 \%, 62.5 \% 0 \%$ and $37.5 \%$, and those treated with Freund's adjuvants were $12.5 \%, 12.5 \%, 12.5 \%, 37.5 \%, 0 \%$ and $25 \%$ respectively. The bacterial lysates vaccinated groups were studied for the total body weight (T), liver (L), spleen (S), thymus (Th) weights and the $\mathrm{L}+\mathrm{S}+\mathrm{Th} / \mathrm{T}$ ratio. Besides, the peripheral blood and the peritoneal fluid total and differential leucocytic counts were determined and the bone marrow lymphocyte percentage. The serum immunoglobulins $\mathrm{G}$ and $\mathrm{M}$ were assessed using the immundiffusion plates. Our conclusion is: Bacterial lysates can play an important role as immunomodulators when used by oral or intranasal routes.
\end{abstract}

\section{Introduction}

Few substances have a greater positive impact upon health care management than antibodies, vaccines and adjuvants . For most of this century, these immunological agents have enjoyed widespread medical applications, predominantly for the treatment, prevention of infectious diseases. Technologies are evolving that are leading to safer, more effective and more cost- efficient vaccines. In Europe, a killed bacterial is referred to as a bacterial vaccine, while in the United States a killed bacterial product is referred to as a bacterin and the term vaccine is reserved for an immunizing agent that contains live inactivated microbial components (Bey et al, 1997). Inactivated whole bacterial cell suspensions are probably the most common type of vaccine used in domestic animals. These vaccines proved to be extremely effective and safe even in young or pregnant animals ,an example is Leptospira vaccines (Kurstak, 1994).

Rutishauser et al. (1998) showed that the use of an oral bacterial lysate was effective in patients with recurrent respiratory tract bacterial infections. Their study demonstrated that the use of an oral bacterial lysate consisting of the antigens of seven bacteria commonly involved in respiratory tract infections has been developed for the induction of specific and non specific immune responses of the mucosa -associated lymphoid tissue. Tablet formulation were taken once daily during two periods of four weeks each. The clinical severity score was significantly lower in patients treated with bacterial lysate compared to patients given placebo. The infection rates revealed reduction of $39 \%$ in children and reduction of $44 \%$ in 
adolescents and adults.On the other hand, bacterial vaccines can be applied effectivly through the intranasal route (Orr et al, 1993 and Ambrosino, 1996). Barackman et al, (1999) showed that intranasal immunization of mice with influenza virus vaccine in combination with the adjuvant LT- R72 induced potent mucosal and serum immunity which was stronger than that with traditional intramuscular immunization. This potently observed immunostimulatory effect can be explained by the natural role of mucosal immune system in defense against inhaled infections (Kiyono et al, 1992).

Bacterial enterotoxin can play a role in vaccination as a mucosal adjuvant also other adjuvants could stimulate mucosal and antibody response (Jackson et al, 1993 and Giuliani et al, 1998).

This study aimed at assessing and comparing the immunoprotective effect of repeated oral and intranasal bacterial lysates using Escherichia coli, Pseudomonas aeroginosa, Staph. aureus, and mixed bacterial lysates.

\section{Material And Methods \\ Bacteria:}

1. Escherichia coli (CAIM- 1357);

2. Pseudomonas aeroginosa ( clinical isolate);

3. Staphylococcus aureus (CAIM-1352);

4. Salmonella typhi;

5. Shigella sp. (NMRO) and

6. Bacillus subtilis (CAIM- 1007).

Bacterial strains used in this study were obtained from the Microbiology Department in NODCAR.

Animals:

Four hundred male albino mice weighing 18- $25 \mathrm{gm}$ each were used in the present study. The animals were obtained from the animal house of ( NODCAR). The animals were divided into four equal groups, control, placebo, intranasal vaccinated and oral vaccinated.

\section{Intranasal vaccinated group:}

This group was subdivided into
I- Bacterial lysate vaccinated group which recived Esch. coli lysate, Ps. aeroginosa lysate, Staph. aureus lysate and mixed bacterial lysates (Corthesy- Theulaz et al, 1998 and Bonenfant et al, 2001).

II- Bacterial lysate mixed with incomplete Freund's adjuvant ( Behripngwerke A. G., Marburg. Germany) in the first dose followed by complete Freund's adjuvant in the next three booster doses (Hanaa,1999 and O'Brien et al, 2000).

Each animal had received $5 \mu \mathrm{l}$ of the vaccine in each nostril, once weekly repeated for four weeks (Sramek et al, 1986 and Raghavan et al, 2002).

\section{Oral vaccinated group}

This group was subdivided as what was previously mentioned before in the intranasal vaccinated animal group.

Each animal had received $10 \mu \mathrm{l}$ of the vaccine orally once weekly repeated for four weeks( Kuenen et al, 1994 ).

\section{Bacterial lysate preparation :}

A 24 hours bacterial growth of Escherichia coli, Pseudomonas aeroginosa, Salmonella typhi, Staphylococcus aureus and Bacillus subtilis that had viable counts $2.72 \times 10^{8}, 7.56 \times 10^{8}, 13.91 \times 10^{8}, 7.33 \times 10^{8}$ and $2.91 \times 10^{8} \mathrm{CFU} / \mathrm{ml}$ respectively was used to prepare the bacterial lysate used in this study. A volume of $25 \mathrm{ml}$ of the 24 hours bacterial growth was lysed using high speed $4000 \mathrm{rpm}$ homogenizer [ variable GKH- GT MOTOR control- Glas- Col (USA) ]. $1 / 100 \mathrm{v} / \mathrm{v}$ of $10 \%$ formalin was added. Then a subculture of the lysates on nutrient agar ( Oxoid) were observed for 24 hours to ensure that the bacterial lysates did not include any viable bacteria (Hugo and Russel, 1993 and Raghavan et al, 2002).

Mixed bacterial lysates were prepared from equal volumes of the different bacterial lysates used in this study (Ruah et $a l, 2001)$.

\section{Bacterial challenge test :}

In the preliminary work of this study, the Pseudomonas aeroginosa LD50 was detrmined. Then the different animal test groups were injected intraperitoneal with LD50 of 24 hours growth of Pseudomonas aeroginosa. The number of mice survivals was recorded in the 48 hours following 
bacterial challenge.( Hamid, 1989 and Bennett- Guerrero et al, 2000).

Immunoglobulins assay :

Serum was obtained from control animals and bacterial lysates treated animals. Serum was divided into aliquots and stored in the freezer until processed. Immunoglobulins $\mathrm{G}$ and $\mathrm{M}$ assays were done using [ Mouse Immunoglobulin 'LL' NANORID- BIND A RID- NANORID PRODUCTS- immundiffusion plates which were supplied by THE BINDING SITE LIMITED Co. UK]. The precipitation rings were measured to an accuracy of $0.1 \mathrm{~mm}$. The assay results were obtained from the calibration table values given by the manufacturer ( Fahey and Mc Kelvey, 1965 and Sadeq et al, 1992).

Haematology assays:

About $0.25 \mathrm{ml}$ blood samples were drawn by capillary tubes from the retroorbital plexus from each mouse, being added to EDTA for peripheral blood total leucocyte count and differntial leucocyte count. Direct smears were withdrawn from the peritoneal fluid for peritoneal total and differential leucocyte counts.Bone marrow smears that were obtained from the femur bone were spreaded for bone marrow lymphocyte count. Leishman stain was used for the different leucocyte counts.

\section{Physiological parameters:}

The total body weight (T) of each animal was recorded, followed by determining the liver(L), spleen(S) and thymus (Th) weights; the $(\mathrm{L}+\mathrm{S}+\mathrm{Th}) / \mathrm{T}$ ratio was determined.

The results were statistically evaluated using the student $t$ - test where the significance of the differences between treated and respective control groups was analysed (Goldstein, 1964) .

\section{Results}

Bacterial challenge test results :

Both oral and intranasal vaccinations could effectively protect the vaccinated mice against Pseudomonas aeroginosa challenge dose. One exception was detected when Pseudomonas aeroginosa bacterial lysate was used for vaccination. Freund's adjuvant alone it could protect against Ps. aerog. challenge dose, and actively potentiated the immunoprotective effect of both oral and intranasal bacterial lysates vaccinations (Table 1 and Fig. 1).

\section{Escherichia coli bacterial lysate vaccination :}

It raised the $\mathrm{L}+\mathrm{S}+\mathrm{Th} / \mathrm{T}$ ratio both in the presence and absence of bacterial challenge when compared with normal control group and placebo group. Besides, the bacterially challenged intranasal vaccinated animal group showed a significant increase in the splenic weight, mean spleen weight \pm SD was $0.398 \pm$ 0.223 ( Table 2). Oral and intranasal Escherichia coli lysate vaccination caused significant increase in the eosinophil counts when compared with normal control and placebo groups (Table 3). Vaccination was associated with increased peritoneal fluid lymphocyte counts (Table 4) and a drop of bone marrow lymphocyte percent-age that were significant when associated with bacterial challenge (Table 5).

\section{Pseudomonas aeroginosa bacterial lysate vaccination :}

It caused an increase in the splenic and thymus weights. Sometimes these changes were associated with significant increase of $\mathrm{L}+\mathrm{S}+\mathrm{Th} / \mathrm{T}$ ratio (Table 6). The peripheral blood haematological findings showed increased eosinophilic counts that were significant when compared with normal control and placebo groups. A significant drop of monocyte count was detected in intranasal vaccinated -bacterial challenged animals (Table 7). Intranasal vaccination with Pseudomonas aeroginosa lysate caused an increase of peritoneal fluid neutrophile count (Table 8) and a drop of bone marrow lymphocyte count (Table 9). It seemed that the different changes recorded in the reticuloendothelial system organs represented by liver, spleen, thymus and $\mathrm{L}+\mathrm{S}+\mathrm{Th} / \mathrm{T}$ ratio and changes observed in haematological findings and bone marrow lymphocytic percentage played a role in increasing lethality rate in intranasal and oral Ps. aerog.- treated mice.

\section{Staphylococcus aureus bacterial lysate vaccination :}

Both oral and intranasal vaccination caused a significant increase of peripheral 
blood total leucocyte count, also a significant increase of thymus weight was observed after intranasal vaccination (Table 10). Peripheral blood differential leucocyte count showed a significant increase of eosinophile count when compared with normal control and placebo groups, this was associated with a significant increase of monocyte count after intranasal vaccination (Table 11). Oral and intranasal vaccinations caused a significant increase of peritoneal fluid leucocyte counts, that was associated with increased monocyte count (Table 12). Staphylococcus aureus lysate orally vaccinated animals showed a drop of bone marrow lymphocyte percentage (Table 13).

Mixed bacterial lysates vaccination :

Mixed bacterial lysates vaccinations caused an increase of splenic weights (Table 14). Peripheral blood showed a significant increase of total leucocyte count and eosinophile count after intranasal and oral vaccinated animal groups. A signifycant drop of neutrophilic percentage associated with a significant increase of lymphocyte count (Table 15). Similar observations were detected in the peritoneal fluid cell counts (Table 16). Bone marrow showed a drop of lymphocytic percentages in the different vaccinated animal groups.

Serum immunoglobulins $\mathbf{G}$ and $M$ :

All bacterial lysate vaccinations led to significant elevation of serum Ig G and Ig $M$, whether after oral or in intranasal vaccination. This response was highly magnified in the presence of bacterial infection due to challenge with Ps. aerog. LD50 (Tables 18-21 and figures 2-5). It seemed that the reported elevation of serum Igs $\mathrm{G}$ and $\mathrm{M}$ were inversely correlated to the death rates reported in ( Table 1 and Fig. 1)

Table (1): Pseudomonas aeroginosa $\mathrm{LD}_{50} *$ bacterial challenge in intranasal and oral bacterial lysate weekly vaccinated mice groups for (four weeks).

\begin{tabular}{|l|c|c|}
\hline \multicolumn{1}{|c|}{$\begin{array}{c}\text { Ps aeroginosa bacterial infection } \\
\text {-challenged mice groups }\end{array}$} & $\begin{array}{c}\text { Intranasal vaccin. } \\
\text { (LD)* }\end{array}$ & $\begin{array}{c}\text { Oral Vaccin. } \\
\text { (LD)* }\end{array}$ \\
\hline Control group (CG) & $50 \%$ & $50 \%$ \\
\hline Freund's adjuv. (FA) & $25 \%$ & $12.5 \%$ \\
\hline Placebo (PT). & $50 \%$ & $50 \%$ \\
\hline Placebo-Freund's adjuv (PF) & $25 \%$ & $12.5 \%$ \\
\hline Esch. coli lysate vaccin. (EL) & $37.5 \%$ & $25 \%$ \\
\hline Esch. coli lysate-Freund's adjuv (EF) & $12.5 \%$ & $12.5 \%$ \\
\hline Pseud. aerog. lysate vaccin. (PL) & $100 \%$ & $62.5 \%$ \\
\hline Pseud. aerog. lysate-Freund's adjuv (PLF) & $62.5 \%$ & $37.5 \%$ \\
\hline Staph. aureus lysate vaccin (SL) & $0 \%$ & $0 \%$ \\
\hline Staph. aureus lysate-Freund's adjuv. (SF) & $0 \%$ & $0 \%$ \\
\hline Mixed bact. Lysate vaccin. (ML) & $12.5 \%$ & $37.5 \%$ \\
\hline Mixed bact. lysate-Freund's adjuv. (MF) & $0 \%$ & $25 \%$ \\
\hline
\end{tabular}

*LD : Lethal dose 
Table (2): Total body weight (T), liver weight $(\mathrm{L})$, spleen weight $(\mathrm{S})$, thymus weight $(\mathrm{Th})$ and $(\mathrm{L}+\mathrm{S}+\mathrm{Th} / \mathrm{T})$ ratio in mice vaccinated with $E s c h$. coli lysate weekly for four weeks.

\begin{tabular}{|l|c|c|c|c|c|}
\hline \multicolumn{1}{|c|}{ Animal group } & $\begin{array}{c}\text { Total body } \\
\text { weight }(\mathbf{T}) \text { in } \\
\text { grams }\end{array}$ & $\begin{array}{c}\text { Liver weight } \\
(\mathbf{L}) \text { in grams }\end{array}$ & $\begin{array}{c}\text { Spleen weight } \\
(\mathbf{S}) \text { in grams }\end{array}$ & $\begin{array}{c}\text { Thymus weight } \\
\text { (Th) in grams }\end{array}$ & $\begin{array}{c}\text { (L+S+Th)/ T } \\
\text { ratio }\end{array}$ \\
\hline 1- Normal control & $22.1 \pm 5.85$ & $1.097 \pm 0.374$ & $0.10 \pm 0.047$ & $0.039 \pm 0.014$ & $0.055 \pm 0.003$ \\
\hline 2- Placebo & $23.3 \pm 4.52$ & $1.056 \pm 0.249$ & $0.076 \pm 0.022$ & $0.041 \pm 0.014$ & $0.057 \pm 0.004$ \\
\hline 3- Ps. aerog bact infect. & $18.5 \pm 3.75$ & $1.159 \pm 0.452$ & $0.113 \pm 0.049$ & $0.026 \pm 0.011$ & $0.069 \pm 0.002 * * *$, \\
ooo
\end{tabular}

$*$,**,*** Significant at $\mathrm{P}<0.05, \mathrm{P}<0.01, \mathrm{P}<0.001$ when compared with gp. (1)

${ }^{\circ},{ }^{\text {oo }}{ }^{\text {ooo }}$ Significant at $\mathrm{P}<0.05, \mathrm{P}<0.01, \mathrm{P}<0.001$ when compared with gp (2).

$\mathrm{x}, \mathrm{xx}, \mathrm{xxx}$ Significant at $\mathrm{P}<0.05, \mathrm{P}<0.01, \mathrm{P}<0.001$ when compared with gp (3).

Table (3): Mice peripheral blood haematological findings after four weekly vaccinations with Esch. coli lysate.

\begin{tabular}{|c|c|c|c|c|c|}
\hline Animal group & $\begin{array}{c}\text { Total } \\
\text { Leucocyte } \\
\text { count } \\
\mathbf{1 0} / \mathbf{c m m} \\
\end{array}$ & $\begin{array}{c}\text { Eosinophil } \\
\%\end{array}$ & $\begin{array}{c}\text { Neutrophils } \\
\%\end{array}$ & $\begin{array}{c}\text { Lymphocytes } \\
\%\end{array}$ & $\begin{array}{c}\text { Monocytes } \\
\%\end{array}$ \\
\hline 1- Normal control & $3.86 \pm 1.68$ & $0.40 \pm 1.8$ & $49.20 \pm 7.1$ & $49.40 \pm 6.1$ & $1.90 \pm 0.7$ \\
\hline 2- Placebo & $3.83 \pm 1.28$ & $0.40 \pm 1.8$ & $48.70 \pm 5.3$ & $48.10 \pm 6.8$ & $1.80 \pm 0.8$ \\
\hline 3- Ps. aerog bact infect. & $4.20 \pm 2.47$ & $\begin{array}{c}3.70 \pm \\
2.3 * * * \text {,oo }\end{array}$ & $50.70 \pm 2.5$ & $51.50 \pm 3.7$ & $2.70 \pm 1.6$ \\
\hline 4- Esch.coli lys. IN vaccin. & $4.32 \pm 1.17$ & $\begin{array}{l}4.20 \pm \\
2.5^{* * *},{ }^{\text {ooo }}\end{array}$ & $45.20 \pm 11.4$ & $46.00 \pm 13.6$ & $3.40 \pm 1.7$ \\
\hline $\begin{array}{l}\text { 5- Esch.coli lys. IN vaccin - } \\
\text { Ps. aerog. bact. infect. }\end{array}$ & $4.64 \pm 2.52$ & $\begin{array}{c}3.40 \pm \\
0.6^{* * *},\end{array}$ & $44.80 \pm 6.3$ & $50.00 \pm 6.4$ & $2.00 \pm 1.4$ \\
\hline 6- Esch.coli lys. oral vaccin. & $3.90 \pm 0.89$ & $3.20 \pm 2.7 * *$ & $44.00 \pm 3.8$ & $50.60 \pm 2.1$ & $2.00 \pm 1.4$ \\
\hline $\begin{array}{l}\text { 7- Esch.coli lys. oral vaccin - } \\
\text { Ps. aerog. bact. infect. }\end{array}$ & $5.55 \pm 2.02$ & $2.80 \pm 1.8^{*}, \mathrm{o}$ & $47.30 \pm 9.3$ & $46.30 \pm 10.4$ & $3.50 \pm 2.3$ \\
\hline
\end{tabular}

$*, * *, * * *$ Significant at $\mathrm{P}<0.05, \mathrm{P}<0.01, \mathrm{P}<0.001$ when compared with gp. (1)

$\stackrel{\circ}{\circ}$, oo Significant at $\mathrm{P}<0.05, \mathrm{P}<0.01, \mathrm{P}<0.001$ when compared with gp (2).

$\mathrm{x}, \mathrm{xx}, \mathrm{xxx}$ Significant at $\mathrm{P}<0.05, \mathrm{P}<0.01, \mathrm{P}<0.001$ when compared with gp (3). 
Table (4): Peritoneal fluid haematological findings in mice after four weekly vaccinations with Esch. coli lysate.

\begin{tabular}{|c|c|c|c|c|c|}
\hline Animal group & $\begin{array}{c}\text { Total } \\
\text { Leucocyte } \\
\text { count } \\
\text { X10 } 3 / \mathrm{cmm} \\
\end{array}$ & $\underset{\%}{\text { Eosinophil }}$ & $\begin{array}{c}\text { Neutrophils } \\
\%\end{array}$ & $\underset{\%}{\text { Lymphocytes }}$ & $\begin{array}{c}\text { Monocytes } \\
\%\end{array}$ \\
\hline 1- Normal control & $3.51 \pm 2.1$ & $0.20 \pm 1.94$ & $52.6 \pm 5.1$ & $43.00 \pm 3.8$ & $1.30 \pm 0.26$ \\
\hline 2- Placebo & $3.08 \pm 1.2$ & $0.10 \pm 1.67$ & $52.8 \pm 5.4$ & $44.10 \pm 3.6$ & $1.10 \pm 0.14$ \\
\hline 3- Ps. aerog bact infect. & $3.35 \pm 1.8$ & $2.80 \pm 3.11$ & $\begin{array}{c}39.8 \pm \\
5.3^{* *, \text { oo }}\end{array}$ & $\begin{array}{c}57.80 \pm \\
8.1 * * *, \text {,oo }\end{array}$ & $0.33 \pm 0.84$ \\
\hline 4- Esch.coli lys. IN vaccin. & $3.10 \pm 1.3$ & $3.40 \pm 0.97$ & $\begin{array}{l}41.00 \pm \\
5.7 * *, \mathrm{oo}\end{array}$ & $\begin{array}{c}58.00 \pm \\
6.2 * * *, \text {,oo }\end{array}$ & $1.00 \pm 1.15$ \\
\hline $\begin{array}{l}\text { 5- Esch.coli lys. IN vaccin - Ps. } \\
\text { aerog. bact. infect. }\end{array}$ & $3.54 \pm 2.6$ & $4.10 \pm 1.36$ & $46.20 \pm 9.3$ & $50.40 \pm 10.6$ & $3.00 \pm 3.74$ \\
\hline 6- Esch.coli lys. oral vaccin. & $4.70 \pm 1.9$ & $2.80 \pm 1.21$ & $\begin{array}{c}38.5 \pm \\
7.7 * * *, \text { ooo }\end{array}$ & $\begin{array}{l}56.50 \pm \\
9.0 * *, \text { oo }\end{array}$ & $\begin{array}{c}3.50 \pm \\
1.92 *, \mathrm{oo}, \mathrm{xx}\end{array}$ \\
\hline $\begin{array}{l}\text { 7- Esch.coli lys. oral vaccin - Ps. } \\
\text { aerog. bact. infect. }\end{array}$ & $\begin{array}{l}7.32 \pm \\
2.6^{*, o, x x}\end{array}$ & $4.70 \pm 2.19$ & $49.8 \pm 9.4$ & $46.80 \pm 10.9$ & $1.70 \pm 1.51$ \\
\hline
\end{tabular}

*,**,***Significant at $\mathrm{P}<0.05, \mathrm{P}<0.01, \mathrm{P}<0.001$ when compared with gp. (1)

$\circ$, oo, oo Significant at $\mathrm{P}<0.05, \mathrm{P}<0.01, \mathrm{P}<0.001$ when compared with gp (2).

$\mathrm{x}, \mathrm{xx}, \mathrm{xxx}$ Significant at $\mathrm{P}<0.05, \mathrm{P}<0.01, \mathrm{P}<0.001$ when compared with gp (3).

Table (5): Mice bone marrow, peripheral blood and peritoneal fluid films lymphocyte percentage after four weekly vaccinations with Esch. coli lysate.

\begin{tabular}{|c|c|c|c|}
\hline Animal group & $\begin{array}{l}\text { Bone marrow } \\
\text { lymphocytes \% }\end{array}$ & $\begin{array}{l}\text { Peripheral blood } \\
\text { lymphocytes \% }\end{array}$ & $\begin{array}{l}\text { Peritoneal fleuid } \\
\text { lymphocytes \% }\end{array}$ \\
\hline 1- Normal control & $41.50 \pm 6.1$ & $49.40 \pm 6.1$ & $43.00 \pm 3.8$ \\
\hline 2- Placebo & $42.00 \pm 5.8$ & $48.10 \pm 6.8$ & $44.10 \pm 3.6$ \\
\hline 3- Ps. aerog bact infect. & $26.50 \pm 2.8 * * *, 000$ & $51.50 \pm 3.7$ & $57.80 \pm 8.1 * * *, 000$ \\
\hline 4- Esch.coli lys. IN vaccin. & $32.50 \pm 9.1$ & $46.00 \pm 13.6$ & $58.00 \pm 6.2 * * *, 000$ \\
\hline $\begin{array}{l}\text { 5- Esch.coli lys. IN vaccin - } \\
\text { Ps. aerog. bact. infect. }\end{array}$ & $29.80 \pm 2.1^{* * *, 000}$ & $50.00 \pm 6.4$ & $50.40 \pm 10.6$ \\
\hline 6- Esch.coli lys. oral vaccin. & $32.00 \pm 2.9 *, 0$ & $50.60 \pm 2.1$ & $56.50 \pm 9.0 * *, 00$ \\
\hline $\begin{array}{l}\text { 7- Esch.coli lys. oral vaccin - } \\
\text { Ps. aerog. bact. infect. }\end{array}$ & $27.70 \pm 4.6^{*, o}$ & $46.30 \pm 10.4$ & $46.80 \pm 10.9$ \\
\hline
\end{tabular}

$*, * *, * * *$ Significant at $\mathrm{P}<0.05, \mathrm{P}<0.01, \mathrm{P}<0.001$ when compared with gp. (1)

o, oo, oo Significant at $\mathrm{P}<0.05, \mathrm{P}<0.01, \mathrm{P}<0.001$ when compared with gp (2).

$\mathrm{x}, \mathrm{Xx}, \mathrm{Xxx}$ Significant at $\mathrm{P}<0.05, \mathrm{P}<0.01, \mathrm{P}<0.001$ when compared with gp (3).

,,$-----\quad$ Significant at $\mathrm{P}<0.05, \mathrm{P}<0.01, \mathrm{P}<0.001$ when compared with previous group. 
Table (6): Total body weight $(\mathrm{T})$, liver weight $(\mathrm{L})$, spleen weight $(\mathrm{S})$, thymus weight $(\mathrm{Th})$ and $(\mathrm{L}+\mathrm{S}+\mathrm{Th} / \mathrm{T})$ ratio in mice vaccinated with Pseudomonas aeroginosa lysate for four weeks.

\begin{tabular}{|c|c|c|c|c|c|}
\hline Animal group & $\begin{array}{c}\text { Total body } \\
\text { weight }(T) \text { in } \\
\text { grams } \\
\end{array}$ & $\begin{array}{l}\text { Liver weight } \\
\text { (L) in grams }\end{array}$ & $\begin{array}{l}\text { Spleen weight } \\
(\mathrm{S}) \text { in grams }\end{array}$ & $\begin{array}{c}\text { Thymus } \\
\text { weight } \\
\text { (Th) in grams } \\
\end{array}$ & $\begin{array}{l}(\mathrm{L}+\mathrm{S}+\mathrm{Th}) / \mathrm{T} \\
\quad \text { ratio }\end{array}$ \\
\hline 1- Normal control & $22.7 \pm 5.4$ & $1.08 \pm 0.35$ & $0.101 \pm 0.03$ & $0.032 \pm 0.02$ & $0.055 \pm 0.007$ \\
\hline 2- Placebo & $23.1 \pm 4.7$ & $1.08 \pm 0.29$ & $0.096 \pm 0.02$ & $0.034 \pm 0.01$ & $0.052 \pm 0.006$ \\
\hline 3- Ps. Aerog. bact infect. & $20.2 \pm 3.8$ & $1.16 \pm 0.45$ & $0.113 \pm 0.04$ & $0.026 \pm 0.01$ & $\underset{0.069 \pm \underset{\mathrm{o}}{0.004}}{0 .}$ \\
\hline 4- Ps. Aerog.lys. IN vaccin. & $24.2 \pm 2.3$ & $1.11 \pm 0.09$ & $\begin{array}{l}0.133 \pm \\
0.02 *, \mathrm{oo}\end{array}$ & $\begin{array}{c}0.062 \pm \\
0.03 * * *, \text { ooo }\end{array}$ & $0.046 \pm 0.002$ \\
\hline $\begin{array}{l}\text { 5- Ps. aerog.lys. IN vaccin } \\
\text { - Ps. aerog. bact. infect. }\end{array}$ & $24.6 \pm 2.7$ & $1.49 \pm 0.35$ & $0.112 \pm 0.03$ & $0.044_{, \mathrm{xx}}^{ \pm} 0.02$ & $\underset{, \mathrm{oo}}{0.071 \pm 0.003} * *$ \\
\hline $\begin{array}{l}\text { 6- Ps. aerog.lys. oral } \\
\text { vaccin. }\end{array}$ & $27.3 \pm 2.1$ & $1.42 \pm 0.17$ & $0.14 \pm 0.04^{*, o o}$ & $0.049 \pm 0.01^{*, \mathrm{o}}$ & $0.066 \pm 0.014$ \\
\hline $\begin{array}{l}\text { 7- Ps. aerog.lys. oral vaccin } \\
\text { - PS. aerog. bact. infect. }\end{array}$ & $23.2 \pm 4.1$ & $1.25 \pm 0.17$ & $0.122 \pm 0.04^{*, o}$ & $0.056 \pm 0.03$ & $0.064 \pm 0.009$ \\
\hline
\end{tabular}

*,**,*** Significant at $\mathrm{P}<0.05, \mathrm{P}<0.01, \mathrm{P}<0.001$ when compared with gp. (1)

$\stackrel{\circ}{ }{ }^{\circ},{ }^{\text {ooo }}$ Significant at $\mathrm{P}<0.05, \mathrm{P}<0.01, \mathrm{P}<0.001$ when compared with gp (2).

$\mathrm{x}, \mathrm{xx}, \mathrm{xxx}$ Significant at $\mathrm{P}<0.05, \mathrm{P}<0.01, \mathrm{P}<0.001$ when compared with gp (3).

-,--,--- $\quad$ Significant at $\mathrm{P}<0.05, \mathrm{P}<0.01, \mathrm{P}<0.001$ when compared with its previous gps.

Table (7): Mice peripheral blood haematological findings after four weekly vaccinations with Pseudomonas aeroginosa lysate.

\begin{tabular}{|c|c|c|c|c|c|}
\hline Animal group & $\begin{array}{c}\text { Total } \\
\text { Leucocyte } \\
\text { count } \\
\mathbf{X 1 0}^{3} / \mathrm{cmm}\end{array}$ & $\begin{array}{c}\text { Eosinophil } \\
\%\end{array}$ & $\begin{array}{c}\text { Neutrophils } \\
\%\end{array}$ & $\begin{array}{c}\text { Lymphocytes } \\
\%\end{array}$ & $\begin{array}{c}\text { Monocytes } \\
\%\end{array}$ \\
\hline 1- Normal control & $3.89 \pm 1.46$ & $0.40 \pm 1.4$ & $48.70 \pm 9.1$ & $46.70 \pm 5.3$ & $1.86 \pm 0.6$ \\
\hline 2- Placebo & $4.01 \pm 1.19$ & $0.40 \pm 1.2$ & $48.20 \pm 6.1$ & $49.20 \pm 7.3$ & $1.81 \pm 0.7$ \\
\hline 3- Ps. aerog. bact infect. & $4.20 \pm 2.47$ & $3.7 \pm 2.3^{* * *, 000}$ & $50.70 \pm 2.5$ & $45.50 \pm 7.4$ & $2.70 \pm 1.6$ \\
\hline 4- Ps aerog. lys. IN vaccin. & $5.83 \pm 1.8$ & $2.00 \pm 0.0 * * *, 000$ & $52.80 \pm 10.2$ & $43.80 \pm 9.7$ & $2.00 \pm 0.0$ \\
\hline $\begin{array}{l}\text { 5- Ps. aerog. lys. IN vaccin }-P S \\
\text { aerog. bact. infect. }\end{array}$ & $5.90 \pm 2.9$ & $1.80 \pm 2.3$ & $51.30 \pm 4.5$ & $48.40 \pm 4.4$ & $\begin{array}{l}0.50 \pm \\
0.2^{*, o}\end{array}$ \\
\hline 6- Ps. aerog. lys. oral vaccin. & $5.35 \pm 1.3$ & $2.00 \pm 0.0 * * *, 000$ & $52.50 \pm 5.7$ & $43.50 \pm 5.7$ & $2.00 \pm 0.0$ \\
\hline $\begin{array}{l}\text { 7- Ps. aerog.lys. oral vaccin - Ps. } \\
\text { aerog. bact. infect. }\end{array}$ & $9.38 \pm 6.9$ & $0.80 \pm 1.0$ & $52.00 \pm 9.2$ & $47.60 \pm 9.2$ & $0.80 \pm 1.1$ \\
\hline
\end{tabular}

$*, * *, * * *$ Significant at $\mathrm{P}<0.05, \mathrm{P}<0.01, \mathrm{P}<0.001$ when compared with gp. (1)

$\stackrel{\circ}{\circ}{ }^{\circ},{ }^{\circ o 0}$ Significant at $\mathrm{P}<0.05, \mathrm{P}<0.01, \mathrm{P}<0.001$ when compared with gp (2). 
Table (8): Peritoneal fluid haematological findings in mice after four weekly vaccinations with Pseudomonas aeroginosa lysate.

\begin{tabular}{|c|c|c|c|c|c|}
\hline Animal group & $\begin{array}{l}\text { Total } \\
\text { Leucocyte } \\
\text { count } \\
\mathrm{X} 10^{3} / \mathrm{cmm}\end{array}$ & $\begin{array}{l}\text { Eosinophil } \\
\%\end{array}$ & $\begin{array}{l}\text { Neutrophils } \\
\%\end{array}$ & $\begin{array}{l}\text { Lymphocytes } \\
\%\end{array}$ & $\begin{array}{l}\text { Monocytes } \\
\%\end{array}$ \\
\hline 1- Normal control & $3.71 \pm 0.9$ & $0.20 \pm 1.87$ & $53.20 \pm 4.8$ & $44.10 \pm 4.3$ & $1.40 \pm 0.31$ \\
\hline 2- Placebo & $3.26 \pm 1.7$ & $0.10 \pm 2.3$ & $52.90 \pm 5.6$ & $42.6 \pm 3.3$ & $1.10 \pm 0.17$ \\
\hline 3- Ps.aerog. bact infect. & $3.84 \pm 2.2$ & $3.30 \pm 3.61$ & $\begin{array}{ll}39.80 & \pm \\
5.3^{* *, 0 o} & \end{array}$ & $\begin{array}{ll}58.30 & \pm \\
7.8^{* * *, \text { ooo }} & \end{array}$ & $0.33 \pm 0.79$ \\
\hline 4- Ps. aerog.lys. IN vaccin. & $6.41 \pm 2.1$ & $0.00 \pm 0.0$ & $\begin{array}{ll}61.00 & \pm \\
2.0^{* *, o o} & \\
\end{array}$ & $38.50 \pm 1.9^{*, o}$ & $0.50 \pm 1.0$ \\
\hline $\begin{array}{l}\text { 5- Ps. aerog.lys. IN vaccin - } \\
\text { Ps. aerog. bact. infect. }\end{array}$ & $5.73 \pm 1.9$ & $2.80 \pm 3.09$ & $61.40 \pm 12.9$ & $37.50 \pm 11.6$ & $0.50 \pm 0.93$ \\
\hline 6- Ps. aerog.lys. oral vaccin. & $7.28 \pm 3.7$ & $1.50 \pm 2.1$ & $44.00 \pm 8.00$ & $55.50 \pm 14.6$ & $0.50 \pm 1.0$ \\
\hline $\begin{array}{l}\text { 7- Ps. aerog.lys. oral vaccin } \\
\text { - Ps. aerog. bact. infect. }\end{array}$ & $5.23 \pm 4.3$ & $1.20 \pm 1.7$ & $66.10 \pm 9.1$ & $33.10 \pm 8.4$ & $0.75 \pm 1.04$ \\
\hline
\end{tabular}

*,**,***Significant at $\mathrm{P}<0.05, \mathrm{P}<0.01, \mathrm{P}<0.001$ when compared with gp. (1)

o, oo, oo Significant at $\mathrm{P}<0.05, \mathrm{P}<0.01, \mathrm{P}<0.001$ when compared with gp (2).

Table (9): Mice bone marrow, peripheral blood and peritoneal fluid films lymphocyte percentage after four weekly vaccinations with Pseudomonas aeroginosa lysate .

\begin{tabular}{|c|c|c|c|}
\hline Animal group & $\begin{array}{l}\text { Bone marrow } \\
\text { lymphocytes \% }\end{array}$ & $\begin{array}{l}\text { Peripheral blood } \\
\text { lymphocytes \% }\end{array}$ & $\begin{array}{l}\text { Peritoneal fleuid } \\
\text { lymphocytes \% }\end{array}$ \\
\hline 1- Normal control & $43.10 \pm 7.1$ & $46.70 \pm 5.3$ & $44.10 \pm 4.3$ \\
\hline 2- Placebo & $42.90 \pm 6.3$ & $49.20 \pm 7.3$ & $42.60 \pm 3.3$ \\
\hline 3- Ps. aerog. bact infect. & $26.50 \pm 2.8^{* * *, 000}$ & $45.50 \pm$ & $58.30 \pm 7.8^{* * *, \text { ooo }}$ \\
\hline 4- Ps. aerog.lys. IN vaccin. & $39.80 \pm 5.8$ & $43.80 \pm 9.7$ & $38.50 \pm 1.9^{* \cdot 0}$ \\
\hline $\begin{array}{l}\text { 5- Ps. aerog.lys. IN vaccin - PS } \\
\text { aerog. bact. infect. }\end{array}$ & $38.50 \pm 16.5$ & $48.40 \pm 4.4$ & $37.50 \pm 11.6$ \\
\hline 6- Ps. aerog.lys. oral vaccin. & $31.60 \pm 1.6^{* *, 00}$ & $43.50 \pm 5.7$ & $55.50 \pm 14.6$ \\
\hline $\begin{array}{l}\text { 7- Ps. aerog.lys. oral vaccin - Ps. } \\
\text { aerog. bact. Infect. }\end{array}$ & $30.50 \pm 5.8^{*, o}$ & $47.60 \pm 9.2$ & $33.10 \pm 8.4$ \\
\hline
\end{tabular}

*,**,***Significant at $\mathrm{P}<0.05, \mathrm{P}<0.01, \mathrm{P}<0.001$ when compared with gp. (1)

$\circ,{ }^{\circ},{ }^{\text {oo }}$ Significant at $\mathrm{P}<0.05, \mathrm{P}<0.01, \mathrm{P}<0.001$ when compared with gp (2).

$\mathrm{x}, \mathrm{xx}, \mathrm{xxx}$ Significant at $\mathrm{P}<0.05, \mathrm{P}<0.01, \mathrm{P}<0.001$ when compared with gp (3).

,,$------\quad$ Significant at $\mathrm{P}<0.05, \mathrm{P}<0.01, \mathrm{P}<0.001$ when compared with previous group. 
Table (10): Total body weight $(\mathrm{T})$, liver weight $(\mathrm{L})$, spleen weight $(\mathrm{S})$, thymus weight $(\mathrm{Th})$ and $(\mathrm{L}+\mathrm{S}+\mathrm{Th} / \mathrm{T})$ ratio in mice vaccinated with Staph. aureus lysate for four weeks.

\begin{tabular}{|l|l|l|l|l|l|}
\hline Animal group & $\begin{array}{l}\text { Total body } \\
\text { weight (T) in } \\
\text { grams }\end{array}$ & $\begin{array}{l}\text { Liver weight } \\
(\mathrm{L}) \text { in grams }\end{array}$ & $\begin{array}{l}\text { Spleen weight } \\
\text { (S) in grams }\end{array}$ & $\begin{array}{l}\text { Thymus } \\
\text { weight } \\
\text { (Th) in grams }\end{array}$ & $\begin{array}{l}\text { (L+S+Th)/ T } \\
\text { ratio }\end{array}$ \\
\hline 1- Normal control & $23.8 \pm 4.63$ & $1.102 \pm 0.401$ & $0.103 \pm 0.036$ & $0.041 \pm 0.013$ & $0.054 \pm 0.003$ \\
\hline 2- Placebo & $23.6 \pm 4.12$ & $1.059 \pm 0.273$ & $0.081 \pm 0.007$ & $0.041 \pm 0.014$ & $0.056 \pm 0.003$ \\
\hline 3- Ps. aerog. bact infect. & $18.7 \pm 3.47$ & $1.169 \pm 0.431$ & $0.117 \pm 0.032$ & $0.026 \pm 0.013$ & $0.069 \pm 0.002$ \\
\hline $\begin{array}{l}\text { 4- Staph. aureus lys. IN } \\
\text { vaccin. }\end{array}$ & $27.7 \pm 2.79$ & $1.18 \pm 0.286$ & $0.117 \pm 0.027$ & 0.061 \\
\hline $\begin{array}{l}\text { 5- Staph. aureus lys. IN } \\
\text { vaccin - Ps. aerog. bact. } \\
\text { infect. }\end{array}$ & $27.4 \pm 1.5$ & $1.29 \pm 0.18$ & $0.133 \pm 0.032$ & $0.004 \pm 0.04000$ & $0.053 \pm 0.004$ \\
\hline $\begin{array}{l}\text { 6-Staph.aureus lys. oral } \\
\text { vaccin }\end{array}$ & $26.3 \pm 1.73$ & $1.26 \pm 0.17$ & $0.127 \pm 0.02$ & $0.051 \pm 0.011$ & $0.054 \pm 0.001$ \\
\hline $\begin{array}{l}\text { 7- Staph. aureus lys. oral } \\
\text { vaccin - Ps. aerog. bact. } \\
\text { Infect }\end{array}$ & $26.6 \pm 2.85$ & $1.13 \pm 0.21$ & $0.131 \pm 0.027$ & $0.046 \pm 0.012$ & $0.051 \pm 0.005$ \\
\hline
\end{tabular}

$*$,**,*** Significant at $\mathrm{P}<0.05, \mathrm{P}<0.01, \mathrm{P}<0.001$ when compared with gp. (1)

${ }^{\circ},{ }^{\text {oo }}$, oo Significant at $\mathrm{P}<0.05, \mathrm{P}<0.01, \mathrm{P}<0.001$ when compared with gp (2).

$\mathrm{x}, \mathrm{xx}, \mathrm{xxx}$ Significant at $\mathrm{P}<0.05, \mathrm{P}<0.01, \mathrm{P}<0.001$ when compared with gp (3).

Significant at $\mathrm{P}<0.05, \mathrm{P}<0.01, \mathrm{P}<0.001$ when compared with its previous $\mathrm{gp}$

Table (11): Mice peripheral blood haematological findings after four weekly vaccinations with Staph. aureus lysate.

\begin{tabular}{|c|c|c|c|c|c|}
\hline Animal group & $\begin{array}{l}\text { Total } \\
\text { Leucocyte } \\
\text { count } \\
\mathrm{X} 10^{3} / \mathrm{cmm}\end{array}$ & $\begin{array}{l}\text { Eosinophil } \\
\%\end{array}$ & $\begin{array}{l}\text { Neutrophils } \\
\%\end{array}$ & $\begin{array}{l}\text { Lymphocytes } \\
\%\end{array}$ & $\begin{array}{l}\text { Monocytes } \\
\%\end{array}$ \\
\hline 1- Normal control & $3.91 \pm 1.26$ & $0.37 \pm 1.2$ & $48.70 \pm 8.7$ & $45.20 \pm 6.1$ & $1.66 \pm 0.31$ \\
\hline 2- Placebo & $4.03 \pm 1.08$ & $0.39 \pm 1.1$ & $46.90 \pm 8.2$ & $48.10 \pm 7.6$ & $1.63 \pm 0.42$ \\
\hline 3- Ps. aerog bact infect. & $4.41 \pm 1.98$ & $\begin{array}{ll}3.9 & \pm \\
2.2^{* * *, 000} & \end{array}$ & $52.10 \pm 3.1$ & $44.90 \pm 6.4$ & $2.91 \pm 1.46$ \\
\hline 4- Staph. aureus lys. IN vaccin. & $\begin{array}{ll}8.35 & \pm \\
2.41^{* *, o o} & \end{array}$ & $\begin{array}{l}2.14 \quad \pm \\
1.35^{* * *, 000}\end{array}$ & $37.60 \pm 4.2$ & $55.10 \pm 4.9$ & $\begin{array}{ll}4.51 & \pm \\
2.93 *, \mathrm{o} & \end{array}$ \\
\hline $\begin{array}{l}\text { 5- Staph. aureus lys. IN vaccin } \\
\text { - Ps. aerog. bact. infect. }\end{array}$ & $6.29 \pm 2.37$ & $\begin{array}{ll}1.25 & \pm \\
1.49^{* *, \mathrm{oo}} & \end{array}$ & $48.30 \pm 2.8$ & $48.90 \pm 2.0$ & $1.63 \pm 1.51$ \\
\hline 6-Staph.aureus lys. oral vaccin & $\begin{array}{ll}8.43 & \pm \\
3.27^{*, o} & \end{array}$ & $\begin{array}{l}2.38 \quad \pm \\
0.74 * * *, \text { ooo }\end{array}$ & $45.60 \pm 8.5$ & $50.50 \pm 9.4$ & $0.51 \pm 0.76$ \\
\hline $\begin{array}{l}\text { 7- Staph. aureus lys. oral vaccin } \\
\text { - Ps. aerog. bact. infect. }\end{array}$ & $5.71 \pm 2.13$ & $\begin{array}{l}2.51 \pm \\
1.41^{* * *, 000} \pm\end{array}$ & $41.30 \pm 6.5$ & $52.90 \pm 10.6$ & $3.00 \pm 3.62$ \\
\hline
\end{tabular}

***,*** Significant at $\mathrm{P}<0.05, \mathrm{P}<0.01, \mathrm{P}<0.001$ when compared with gp. (1)

o, oo, oo Significant at $\mathrm{P}<0.05, \mathrm{P}<0.01, \mathrm{P}<0.001$ when compared with gp (2).

$\mathrm{x}, \mathrm{xx}, \mathrm{xxx}$ Significant at $\mathrm{P}<0.05, \mathrm{P}<0.01, \mathrm{P}<0.001$ when compared with gp (3).

,,$------\quad$ Significant at $\mathrm{P}<0.05, \mathrm{P}<0.01, \mathrm{P}<0.001$ when compared with its previous gp 
Table (12): Peritoneal fluid haematological findings in mice after four weekly vaccinations with Staph. aurerus lysate

\begin{tabular}{|c|c|c|c|c|c|}
\hline Animal group & $\begin{array}{l}\text { Total Leucocyte } \\
\text { count } \mathrm{X} 10^{3} / \mathrm{cmm}\end{array}$ & $\begin{array}{l}\text { Eosinophil } \\
\%\end{array}$ & $\begin{array}{l}\text { Neutrophils } \\
\%\end{array}$ & $\begin{array}{l}\text { Lymphocytes } \\
\%\end{array}$ & $\begin{array}{l}\text { Monocytes } \\
\%\end{array}$ \\
\hline 1- Normal control & $3.41 \pm 0.87$ & $0.21 \pm 1.77$ & $52.70 \pm 4.1$ & $44.96 \pm 4.7$ & $1.31 \pm 0.42$ \\
\hline 2- Placebo & $3.05 \pm 0.91$ & $0.17 \pm 1.91$ & $52.81 \pm 4.7$ & $43.23 \pm 3.9$ & $1.11 \pm 0.57$ \\
\hline 3-PS aerrog bact infect. & $3.94 \pm 2.01$ & $3.21 \pm 3.49$ & $39.92 \pm 4.9$ & $\begin{array}{ll}58.39 & \pm \\
6.2 * * *, \text { ooo } & \end{array}$ & $\begin{array}{ll}0.37 & \pm \\
0.791 & \end{array}$ \\
\hline $\begin{array}{l}\text { 4- Staph. aureus lys. IN } \\
\text { vaccin. }\end{array}$ & $3.86 \pm 1.10$ & $0.00 \pm 0.0$ & $56.63 \pm 9.3$ & $39.63 \pm 8.2$ & $3.50 \pm 2.39$ \\
\hline $\begin{array}{l}\text { 5- Staph. aureus lys. IN } \\
\text { vaccin - Ps. aerog. bact. } \\
\text { infect. }\end{array}$ & $8.89 \pm 4.3^{* *, o 0}$ & $0.25 \pm 0.66$ & $48.63 \pm 7.9$ & $48.38 \pm 8.9$ & $\begin{array}{ll}3.00 & \pm \\
1.19^{*, o, x} & \end{array}$ \\
\hline $\begin{array}{l}\text { 6-Staph.aureus lys. oral } \\
\text { vaccin }\end{array}$ & $7.40 \pm 2.5^{* *, o o}$ & $0.00 \pm 0.0$ & $53.00 \pm 7.7$ & $42.11 \pm 7.89$ & $\begin{array}{l}3.00 \quad \pm \\
0.93 * *, \text { oo }\end{array}$ \\
\hline $\begin{array}{l}\text { 7- Staph. aureus lys. } \\
\text { oral vaccin - Ps. aerog. } \\
\text { bact. infect. }\end{array}$ & $11.63 \pm 4.5^{* * *, 000, x \times x}$ & $0.25 \pm 0.66$ & $\begin{array}{l}51.38 \\
11.7\end{array}$ & $45.13 \pm 11.14$ & $\begin{array}{l}3.25 \pm 1.82 \\
x\end{array}$ \\
\hline
\end{tabular}

$*, * *, * * *$ Significant at $\mathrm{P}<0.05, \mathrm{P}<0.01, \mathrm{P}<0.001$ when compared with gp. (1)

${ }^{\circ},{ }^{\text {oo, }}$, ${ }^{\text {oo }}$ Significant at $\mathrm{P}<0.05, \mathrm{P}<0.01, \mathrm{P}<0.001$ when compared with gp (2).

$\mathrm{x}, \mathrm{xx}, \mathrm{xxx}$ Significant at $\mathrm{P}<0.05, \mathrm{P}<0.01, \mathrm{P}<0.001$ when compared with gp (3).

Table (13): Mice bone marrow, peripheral blood and peritoneal fluid films lymphocyte percentage after four weekly vaccinations with Staph. aureus lysate.

\begin{tabular}{|c|c|c|c|}
\hline Animal group & $\begin{array}{c}\text { Bone marrow } \\
\text { lymphocytes \% }\end{array}$ & $\begin{array}{c}\text { Peripheral blood } \\
\text { lymphocytes \% }\end{array}$ & $\begin{array}{c}\text { Peritoneal fleuid } \\
\text { lymphocytes } \%\end{array}$ \\
\hline 1- Normal control & $42.10 \pm 4.8$ & $45.20 \pm 6.1$ & $44.90 \pm 4.7$ \\
\hline 2- Placebo & $43.10 \pm 5.1$ & $48.10 \pm 7.6$ & $43.20 \pm 3.9$ \\
\hline 3- Ps. aerog bact infect. & $25.60 \pm 3.01$ & $44.90 \pm 6.4$ & $38.40 \pm 6.2 * * *, 000$ \\
\hline $\begin{array}{c}\text { 4- Staph. aureus lys. IN } \\
\text { vaccin. }\end{array}$ & $40.30 \pm 2.32$ & $55.10 \pm 4.9$ & $48.40 \pm 8.9$ \\
\hline $\begin{array}{c}\text { 5- Staph. aureus lys. IN } \\
\text { vaccin - Ps. aerog. bact. } \\
\text { infect. }\end{array}$ & $44.10 \pm 2.48$ & $48.90 \pm 2.0$ & $42.10 \pm 7.9$ \\
\hline $\begin{array}{c}\text { 6- Staph. aureus lys. oral } \\
\text { vaccin. }\end{array}$ & $33.80 \pm 2.12^{*, 0}$ & $50.50 \pm 9.4$ & $45.10 \pm 11.1$ \\
\hline $\begin{array}{c}\text { 7- Staph. aureus lys. oral } \\
\text { vaccin - Ps.. aerog. bact. } \\
\text { infect. }\end{array}$ & $35.40 \pm 7.3$ & $52.90 \pm 10.6$ & \\
\hline
\end{tabular}

$*$,**,*** Significant at $\mathrm{P}<0.05, \mathrm{P}<0.01, \mathrm{P}<0.001$ when compared with gp. (1)

$\circ,{ }^{\circ},{ }^{\text {oo }}$ Significant at $\mathrm{P}<0.05, \mathrm{P}<0.01, \mathrm{P}<0.001$ when compared with gp (2).

,,$------\quad$ Significant at $\mathrm{P}<0.05, \mathrm{P}<0.01, \mathrm{P}<0.001$ when compared with gp (3).

$\mathrm{x}, \mathrm{xx}, \mathrm{xxx}$ Significant at $\mathrm{P}<0.05, \mathrm{P}<0.01, \mathrm{P}<0.001$ when compared with previous group. 
Table (14): Total body weight (T), liver weight $(\mathrm{L})$, spleen weight $(\mathrm{S})$, thymus weight (Th) and $(\mathrm{L}+\mathrm{S}+\mathrm{Th} / \mathrm{T})$ ratio in mice vaccinated with mixed bacterial lysates weekly for four weeks .

\begin{tabular}{|c|c|c|c|c|c|}
\hline Animal group & $\begin{array}{l}\text { Total body } \\
\text { weight }(\mathrm{T}) \\
\text { in grams }\end{array}$ & $\begin{array}{l}\text { Liver } \\
\text { weight } \\
\text { (L) in } \\
\text { grams }\end{array}$ & $\begin{array}{l}\text { Spleen } \\
\text { weight } \\
(\mathrm{S}) \\
\text { grams }\end{array}$ & $\begin{array}{l}\text { Thymus } \\
\text { weight } \\
\text { (Th) in } \\
\text { grams }\end{array}$ & $\begin{array}{l}(\mathrm{L}+\mathrm{S}+\mathrm{Th}) / \mathrm{T} \\
\text { ratio }\end{array}$ \\
\hline 1- Normal control & $23.2 \pm 4.65$ & $1.19 \pm 0.34$ & $\begin{array}{l}0.102 \\
0.042\end{array}$ & $\begin{array}{l}0.039 \\
0.014\end{array}$ & $0.057 \pm 0.007$ \\
\hline 2- Placebo & $23.6 \pm 4.13$ & $1.09 \pm 0.27$ & $\begin{array}{l}0.089 \\
0.022\end{array}$ & $\begin{array}{l}0.046 \\
0.016\end{array}$ & $0.054 \pm 0.006$ \\
\hline 3- Ps. aerog bact infect. & $18.5 \pm 3.74$ & $1.16 \pm 0.45$ & $\begin{array}{l}0.113 \\
0.048\end{array}$ & $0.026 \pm 0.01$ & $0.069 \pm 0.004^{*, o}$ \\
\hline 4- Mixed bact. Lys. IN vaccin. & $25.1 \pm 2.84$ & $1.06 \pm 0.07$ & $\begin{array}{l}0.117 \\
0.023\end{array}$ & $\begin{array}{l}0.072 \\
0.112\end{array}$ & $0.049 \pm 0.01$ \\
\hline $\begin{array}{l}\text { 5- Mixed bact. Lys. IN vaccin } \\
\text { - Ps. aerog. Bact. Infect. }\end{array}$ & $22.3 \pm 3.44$ & $1.23 \pm 0.22$ & $\begin{array}{l}0.127 \\
0.037\end{array}$ & $\begin{array}{l}0.030 \\
0.012\end{array}$ & $0.062 \pm 0.003$ \\
\hline $\begin{array}{llll}6- & \text { Mixed bact. Lys. oral } \\
\text { vaccin. } & & & \\
\text { vacin }\end{array}$ & $26.4 \pm 3.56$ & $1.18 \pm 0.18$ & $\begin{array}{l}0.139 \\
0.039\end{array}$ & $\begin{array}{l}0.034 \\
0.012\end{array}$ & $0.051 \pm 0.006$ \\
\hline $\begin{array}{l}\text { 7- } \text { Mixed bact. Lys. oral } \\
\text { vaccin-Ps. aerog. bact. infect. }\end{array}$ & $22.0 \pm 2.58$ & $0.93 \pm 0.22$ & $\begin{array}{l}0.123 \\
0.032\end{array}$ & $\begin{array}{l}0.036 \\
0.008\end{array}$ & $0.049 \pm 0.005$ \\
\hline
\end{tabular}

$*, * *, * * *$ Significant at $\mathrm{P}<0.05, \mathrm{P}<0.01, \mathrm{P}<0.001$ when compared with gp. (1)

$\circ{ }^{\circ}$, oo Significant at $\mathrm{P}<0.05, \mathrm{P}<0.01, \mathrm{P}<0.001$ when compared with gp (2).

$\mathrm{x}, \mathrm{xx}, \mathrm{xxx}$ Significant at $\mathrm{P}<0.05, \mathrm{P}<0.01, \mathrm{P}<0.001$ when compared with gp (3).

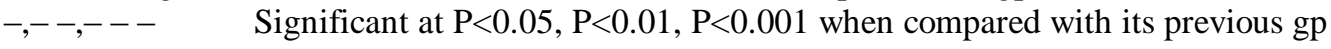

Table (15): Mice peripheral blood haematological findings after four weekly vaccinations with mixed bacterial lysates .

\begin{tabular}{|c|c|c|c|c|c|}
\hline Animal group & $\begin{array}{l}\text { Total } \\
\text { Leucocyte } \\
\text { count } \\
\mathrm{X} 10^{3} / \mathrm{cmm}\end{array}$ & $\begin{array}{l}\text { Eosinophil } \\
\%\end{array}$ & $\begin{array}{l}\text { Neutrophils } \\
\%\end{array}$ & $\begin{array}{l}\text { Lymphocytes } \\
\%\end{array}$ & $\begin{array}{l}\text { Monocytes } \\
\%\end{array}$ \\
\hline 1- Normal control & $3.86 \pm 1.27$ & $0.40 \pm 1.6$ & $48.70 \pm 8.1$ & $50.10 \pm 5.91$ & $1.90 \pm 0.87$ \\
\hline 2- Placebo & $3.86 \pm 1.19$ & $0.40 \pm 1.6$ & $47.10 \pm 9.6$ & $49.30 \pm 6.43$ & $1.80 \pm 0.66$ \\
\hline 3- Ps. aerog bact infect. & $4.12 \pm 2.33$ & $\begin{array}{l}3.67 \quad \pm \\
2.34 * * * \text {,ooo }\end{array}$ & $50.70 \pm 2.48$ & $51.50 \pm 3.62$ & $2.67 \pm 1.63$ \\
\hline 4- Mixed bact. Lys. IN vaccin. & $\begin{array}{l}6.61 \\
0.39 * * *, \text { ooo }\end{array}$ & $\begin{array}{ll}2.00 & \pm \\
1.19^{* *, \mathrm{oo}} & \end{array}$ & $\begin{array}{ll}32.80 & \pm \\
6.64 * *, \text { oo } & \end{array}$ & $\begin{array}{l}63.60 \quad \pm \\
6.05^{* * *, 000}\end{array}$ & $1.50 \pm 0.76$ \\
\hline $\begin{array}{l}\text { 5- Mixed bact. Lys. IN vaccin } \\
\text { - Ps. aerog. bact. infect. }\end{array}$ & $\begin{array}{l}6.76 \quad \pm \\
2.38 * * *, \text { ooo, } x\end{array}$ & $1.14 \pm 1.57^{-}$ & $46.10 \pm 5.8^{-}$ & $49.80 \pm 7.36^{-}$ & $2.86 \pm 2.55$ \\
\hline $\begin{array}{l}\text { 6- Mixed bact. Lys. oral } \\
\text { vaccin. }\end{array}$ & $4.84 \pm 1.81$ & $\begin{array}{l}3.00 \quad \pm \\
1.77 * * * \text {,ooo }\end{array}$ & $\begin{array}{ll}42.50 & \pm \\
2.93 * *, \text { oo } & \end{array}$ & $50.60 \pm 4.77$ & $5.00 \pm 2.0$ \\
\hline $\begin{array}{l}\text { 7- Mixed bact. Lys. oral } \\
\text { vaccin- Ps. aerog. bact. infect. }\end{array}$ & $\begin{array}{l}7.37 \underset{2.51 * * *, \text { ooo }, \mathrm{x}}{ \pm} \\
\end{array}$ & $\begin{array}{l}3.60 \quad \pm \\
2.16^{* * *, 000}\end{array}$ & $\underset{-, x x}{46.80 \pm 1.04^{-}}$ & $46.80 \pm 2.13$ & $2.83 \pm 0.98$ \\
\hline
\end{tabular}

$*, * *, * * *$ Significant at $\mathrm{P}<0.05, \mathrm{P}<0.01, \mathrm{P}<0.001$ when compared with gp. (1)

$\circ,{ }^{\circ}$, oo Significant at $\mathrm{P}<0.05, \mathrm{P}<0.01, \mathrm{P}<0.001$ when compared with gp (2).

$\mathrm{x}, \mathrm{xx}, \mathrm{xxx}$ Significant at $\mathrm{P}<0.05, \mathrm{P}<0.01, \mathrm{P}<0.001$ when compared with gp (3).

,,$-----\quad$ Significant at $\mathrm{P}<0.05, \mathrm{P}<0.01, \mathrm{P}<0.001$ when compared with its previous gp 
Table (16): Peritoneal fluid haematological findings in mice after four weekly vaccinations with mixed bacterial lysates.

\begin{tabular}{|c|c|c|c|c|c|}
\hline Animal group & $\begin{array}{l}\text { Total } \\
\text { Leucocyte } \\
\text { count } \\
\text { X10 } / \mathrm{cmm}\end{array}$ & $\begin{array}{l}\text { Eosinophil } \\
\%\end{array}$ & $\begin{array}{l}\text { Neutrophils } \\
\%\end{array}$ & $\begin{array}{l}\text { Lymphocytes } \\
\%\end{array}$ & $\begin{array}{l}\text { Monocytes } \\
\%\end{array}$ \\
\hline 1- Normal control & $3.61 \pm 1.81$ & $0.38 \pm 1.02$ & $54.70 \pm 4.31$ & $41.70 \pm 4.11$ & $1.30 \pm 0.6$ \\
\hline 2- Placebo & $3.20 \pm 1.22$ & $0.38 \pm 1.02$ & $52.80 \pm 3.16$ & $42.90 \pm 5.16$ & $1.10 \pm 0.7$ \\
\hline 3- Ps. aerog bact infect. & $3.35 \pm 2.06$ & $0.50 \pm 3.40$ & $\begin{array}{ll}39.80 & \pm \\
8.75^{* *, \text { oo }} & \end{array}$ & $\begin{array}{ll}57.80 & \pm \\
8.92 * * *, \text { ooo } & \end{array}$ & $0.33 \pm 0.82$ \\
\hline 4- Mixed bact. Lys. IN vaccin. & $\begin{array}{ll}1.89 & \pm \\
0.84^{*, o} & \end{array}$ & $0.00 \pm 0.0$ & $55.50 \pm 6.99$ & $42.00 \pm 6.53$ & $2.13 \pm 1.25$ \\
\hline $\begin{array}{l}\text { 5- Mixed bact. Lys. IN vaccin } \\
\text { - Ps. aerog. bact. infect. }\end{array}$ & $4.46 \pm 2.66$ & $0.25 \pm 0.04$ & $\begin{array}{ll}56.40 & \pm \\
11.92^{\mathrm{x}} & \end{array}$ & $43.10 \pm 12.32$ & $0.75 \pm 1.04$ \\
\hline 6-Mixed bact. Lys. oral vaccn. & $\begin{array}{ll}6.68 & \pm \\
1.21 * *, \text { oo } & \end{array}$ & $0.00 \pm 0.0$ & $\begin{array}{l}64.50 \pm \\
5.33^{* * *, \text { ooo }} \pm\end{array}$ & $33.00 \pm 7.62$ & $2.13 \pm 1.25$ \\
\hline $\begin{array}{l}\text { 7- Mixed bact. Lys. oral } \\
\text { vaccin- Ps. aerog. bact. infect. }\end{array}$ & $5.23 \pm 3.76$ & $0.25 \pm 0.02$ & $\begin{array}{ll}60.00 & \pm \\
8.39 *, \mathbf{o}, \mathrm{x} & \end{array}$ & $\begin{array}{l}38.90 \\
9.71^{\mathrm{xx}}\end{array}$ & $0.89 \pm 1.45$ \\
\hline
\end{tabular}

$*$,**,*** Significant at $\mathrm{P}<0.05, \mathrm{P}<0.01, \mathrm{P}<0.001$ when compared with gp. (1)

$\circ$, oo, oo Significant at $\mathrm{P}<0.05, \mathrm{P}<0.01, \mathrm{P}<0.001$ when compared with gp (2).

$\mathrm{x}, \mathrm{xx}, \mathrm{xxx}$ Significant at $\mathrm{P}<0.05, \mathrm{P}<0.01, \mathrm{P}<0.001$ when compared with gp (3).

-,-,$---\quad$ Significant at $\mathrm{P}<0.05, \mathrm{P}<0.01, \mathrm{P}<0.001$ when compared with its previous gp

Table (17):Mice bone marrow, peripheral blood and peritoneal fluid films lymphocyte percentage after four weekly vaccinations with mixed bacterial lysates .

\begin{tabular}{|l|c|c|c|}
\hline Animal group & $\begin{array}{c}\text { Bone marrow } \\
\text { lymphocytes } \%\end{array}$ & $\begin{array}{c}\text { Peripheral blood } \\
\text { lymphocytes } \%\end{array}$ & $\begin{array}{c}\text { Peritoneal fleuid } \\
\text { lymphocytes } \%\end{array}$ \\
\hline 1- Normal control & $41.90 \pm 5.9$ & $50.10 \pm 5.91$ & $41.70 \pm 4.11$ \\
\hline 2- Placebo & $42.80 \pm 5.4$ & $49.30 \pm 6.43$ & $42.90 \pm 5.16$ \\
\hline 3- Ps. aerrog bact infect. & $25.90 \pm 2.92^{* * *, 000}$ & $51.50 \pm 3.62$ & $57.80 \pm 8.92^{* * *, 000}$ \\
\hline $\begin{array}{l}\text { 4- Mixed bact. lys. IN vaccin. } \\
\text { 5- Mixed bact. lys. IN vaccin - } \\
\text { Ps. aerog. bact. infect. }\end{array}$ & $30.10 \pm 1.64^{* * *, 000}$ & $63.60 \pm 6.05^{* * *, o 00}$ & $42.00 \pm 6.53$ \\
\hline $\begin{array}{l}\text { 6- Mixed bact. lys. oral vaccin. } \\
\text { 7- Mixed bact. lys. oral vaccin - } \\
\text { PS. } \text { aerog. bact. infect. }\end{array}$ & $35.30 \pm 4.31^{---, \mathrm{xx}}$ & $49.80 \pm 7.63^{--}$ & $43.10 \pm 12.32$ \\
\hline
\end{tabular}

***,*** Significant at $\mathrm{P}<0.05, \mathrm{P}<0.01, \mathrm{P}<0.001$ when compared with gp. (1)

$\circ$, oo, ooo Significant at $\mathrm{P}<0.05, \mathrm{P}<0.01, \mathrm{P}<0.001$ when compared with gp (2).

$\mathrm{x}, \mathrm{xx}, \mathrm{xxx}$ Significant at $\mathrm{P}<0.05, \mathrm{P}<0.01, \mathrm{P}<0.001$ when compared with gp (3).

,,$------\quad$ Significant at $\mathrm{P}<0.05, \mathrm{P}<0.01, \mathrm{P}<0.001$ when compared with its previous gp 
Table (18): Mice serum IgM and IgG levels after four weekly vaccinations with Esch. coli lysate $\boldsymbol{\Lambda}$.

\begin{tabular}{|c|c|c|}
\hline Animal group & Serum IgM $(\mathrm{mg} / \mathrm{L}) \boldsymbol{\Delta}$ & Serum $\operatorname{IgG}(\mathrm{mg} / \mathrm{L}) \boldsymbol{\Delta}$ \\
\hline 1- Normal control ( C) & $16.70 \pm 0.58$ & $25.7 \pm 8.51$ \\
\hline 2- Placebo (P) & $16.5 \pm 0.56$ & $24.3 \pm 7.81$ \\
\hline 3- Ps. aerog. bact infect. (PSI) & $25.4 \pm 2.21 * * *,{ }^{\text {ooo }}$ & $39.5 \pm 2.43^{* *, \mathrm{oo}}$ \\
\hline 4- Esch. coli lys. IN vaccin. (EIN) & $26.80 \pm 1.84 * * *$, ooo & $22.50 \pm 4.57$ \\
\hline $\begin{array}{l}\text { 5- Esch. coli lys. IN vaccin }-P s . \\
\text { aerog. bact. infect. (EINI) }\end{array}$ & $28.50 \pm 1.04 * * *$, ooo & $79.10 \pm 4.08 * * *,{ }^{\text {ooo }}$ \\
\hline 6- Esch. coli lys. oral vaccin. (EO) & $24.2 \pm 2.49 * *{ }^{\text {ooo }}$ & $38.4 \pm 2.89 * *{ }^{\text {ooo }}$ \\
\hline $\begin{array}{l}\text { 7- Esch. coli lys. oral vaccin - Ps. } \\
\text { aerog. bact. infect. (EOI) }\end{array}$ & $28.60 \pm 1.09 * * *$, oo & $75.7 \pm 6.57 * * *$, ooo \\
\hline
\end{tabular}

*,**,***Significant at $\mathrm{P}<0.05, \mathrm{P}<0.01, \mathrm{P}<0.001$, respectively, when compared with normal control group.

$\stackrel{\circ}{\circ}{ }^{\text {oo }}{ }^{\text {oo }}$ Significant at $\mathrm{P}<0.05, \mathrm{P}<0.01, \mathrm{P}<0.001$, respectively, when compared with placebo treated group

A Using plate diffusion method.

Table (19): Mice serum IgM and IgG levels after four weekly vaccinations with Pseudomona aeroginosa lysate $\Delta$.

\begin{tabular}{|c|c|c|}
\hline Animal group & Serum $\operatorname{IgM}(\mathrm{mg} / \mathrm{L}) \boldsymbol{\Delta}$ & Serum IgG $(\mathrm{mg} / \mathrm{L}) \boldsymbol{\Delta}$ \\
\hline 1- Normal control ( C) & $16.70 \pm 0.58$ & $25.7 \pm 8.51$ \\
\hline 2- Placebo $(\mathrm{P})$ & $16.5 \pm 0.56$ & $24.3 \pm 7.81$ \\
\hline 3- Ps. aerog. bact infect. (PSI) & $25.4 \pm 2.21 * * *,{ }^{\circ 00}$ & $39.5 \pm 2.43 * *$, oo \\
\hline 4- Ps. aerog lys. IN vaccin. (PSIN) & $21.4 \pm 1.48 * *$, oo & $43.1 \pm 3.66 * * *$, ooo \\
\hline $\begin{array}{l}\text { 5-Ps aerog.lys. IN vaccin }- \text { Ps. aerog. bact. } \\
\text { infect. (PSINI) }\end{array}$ & $26.2 \pm 2.51 * * *, 000$ & $79.40 \pm 3.10^{* * *},{ }^{\text {ooo }}$ \\
\hline 6-Ps. aerog. lys. oral vaccin. (PSO) & $24.60 \pm 2.69 * * *,{ }^{\text {ooo }}$ & $43.0 \pm 3.42 * * *$, ooo \\
\hline $\begin{array}{l}\text { 7-Ps aerog. lys. oral vaccin - Ps. aerog. bact. } \\
\text { infect. (PSOI) }\end{array}$ & $27.6 \pm 3.05 * * *$,oo & $85.6 \pm 3.23 * * *,{ }^{\text {ooo }}$ \\
\hline
\end{tabular}

*,**,***Significant at $\mathrm{P}<0.05, \mathrm{P}<0.01, \mathrm{P}<0.001$, respectively, when compared with normal control group. ${ }^{\circ},{ }^{\text {oo }}{ }^{\text {ooo }}$ Significant at $\mathrm{P}<0.05, \mathrm{P}<0.01, \mathrm{P}<0.001$, respectively, when compared with placebo treated group

$\Delta \quad$ Using plate diffusion method.

Table (20): Mice serum IgM and IgG levels after four weekly vaccinations with Staph. aureus lysate $\boldsymbol{\Delta}$.

\begin{tabular}{|c|c|c|}
\hline Animal group & Serum $\operatorname{IgM}(\mathrm{mg} / \mathrm{L}) \boldsymbol{\Delta}$ & Serum IgG $(\mathrm{mg} / \mathrm{L}) \boldsymbol{\Delta}$ \\
\hline 1- Normal control ( C) & $16.70 \pm 0.58$ & $25.7 \pm 8.51$ \\
\hline 2- Placebo $(\mathrm{P})$ & $16.5 \pm 0.56$ & $24.3 \pm 7.81$ \\
\hline 3- Ps. aerog. bact infect. (PSI) & $25.4 \pm 2.21 * * *,{ }^{\circ 00}$ & $39.5 \pm 2.43 * *$, oo \\
\hline 4- Staph. aureus lys. IN vaccin. (SIN) & $22.9 \pm 6.61 * * *$, ooo & $42.9 \pm 4.19 * *$, oo \\
\hline $\begin{array}{l}\text { 5- Staph. aureus lys. IN vaccin - Ps. aerog. } \\
\text { bact. infect. SINI) }\end{array}$ & $29.4 \pm 4.11 * * *$,oo & $49.70 \pm 4.81 * * *,{ }^{\text {ooo }}$ \\
\hline 6- Staph. aureus lys. oral vaccin. (SO) & $21.70 \pm 4.73 * * *$,oo & $43.90 \pm 5.02 * * *$, ooo \\
\hline $\begin{array}{l}\text { 7- Staph. aureus lys. oral vaccin - Ps. aerog. } \\
\text { bact. Infect. (SOI) }\end{array}$ & $32.4 \pm 5.64 * * *$,oo & $65.6 \pm 5.23 * * *$, ,oo $^{2}$ \\
\hline
\end{tabular}

$*$,**,*** Significant at $\mathrm{P}<0.05, \mathrm{P}<0.01, \mathrm{P}<0.001$, respectively, when compared with normal control group.

${ }^{\circ},{ }^{o o}$, oo Significant at $\mathrm{P}<0.05, \mathrm{P}<0.01, \mathrm{P}<0.001$, respectively, when compared with placebo treated group

$\Delta \quad$ Using plate diffusion method. 
Table (21): Mice serum IgM and IgG levels after four weekly vaccinations with mixed bacterial lysates $\Delta$.

\begin{tabular}{|c|c|c|}
\hline Animal group & Serum $\operatorname{IgM}(\mathrm{mg} / \mathrm{L}) \boldsymbol{\Lambda}$ & Serum IgG $(\mathrm{mg} / \mathrm{L}) \boldsymbol{\Delta}$ \\
\hline 1- Normal control ( C) & $16.70 \pm 0.58$ & $25.7 \pm 8.51$ \\
\hline 2- Placebo $(\mathrm{P})$ & $16.5 \pm 0.56$ & $24.3 \pm 7.81$ \\
\hline 3- Ps. aerog. bact infect. (PSI) & $25.4 \pm 2.21 * * *,{ }^{\text {,oo }}$ & $39.5 \pm 2.43^{* *, 00}$ \\
\hline 4- Mixed bact. lys. IN vaccin. (MIN) & $20.90 \pm 3.64^{*, o}$ & $39.2 \pm 4.17 *{ }^{\circ}$ \\
\hline $\begin{array}{l}\text { 5- Mixed bact. lys. IN vaccin - Ps. aerog. bact. } \\
\text { infect. (MINI) }\end{array}$ & $26.30 \pm 3.91 * * *$,oo & $83.0 \pm 6.28 * * *, 000$ \\
\hline 6- Mixed bact. lys. oral vaccin. (MO) & $22.40 \pm 3.29 * *$,oo & $42.1 \pm 5.89 * *,{ }^{\circ}$ \\
\hline $\begin{array}{l}\text { 7- Mixed bact. lys. oral vaccin - Ps. aerog. } \\
\text { bact. infect. (MOI) }\end{array}$ & $28.6 \pm 4.72 * * *$, ooo & $65.6 \pm 7.82 * * *, 000$ \\
\hline
\end{tabular}

$* * * * * *$ Significant at $\mathrm{P}<0.05, \mathrm{P}<0.01, \mathrm{P}<0.001$, respectively, when compared with normal control group. o, oo, ooo Significant at $\mathrm{P}<0.05, \mathrm{P}<0.01, \mathrm{P}<0.001$, respectively, when compared with placebo treated group. $\Delta \quad$ Using plate diffusion method.

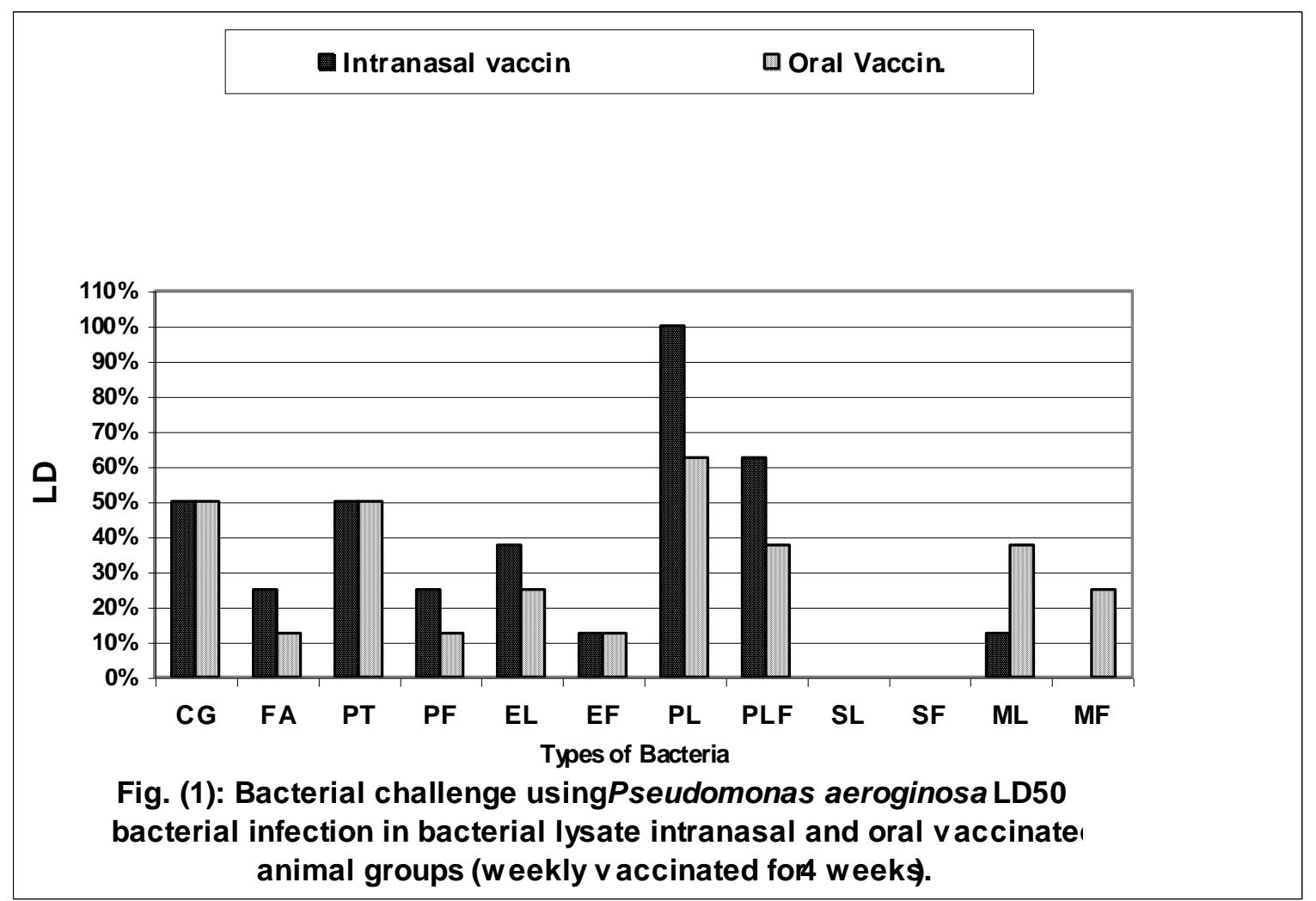



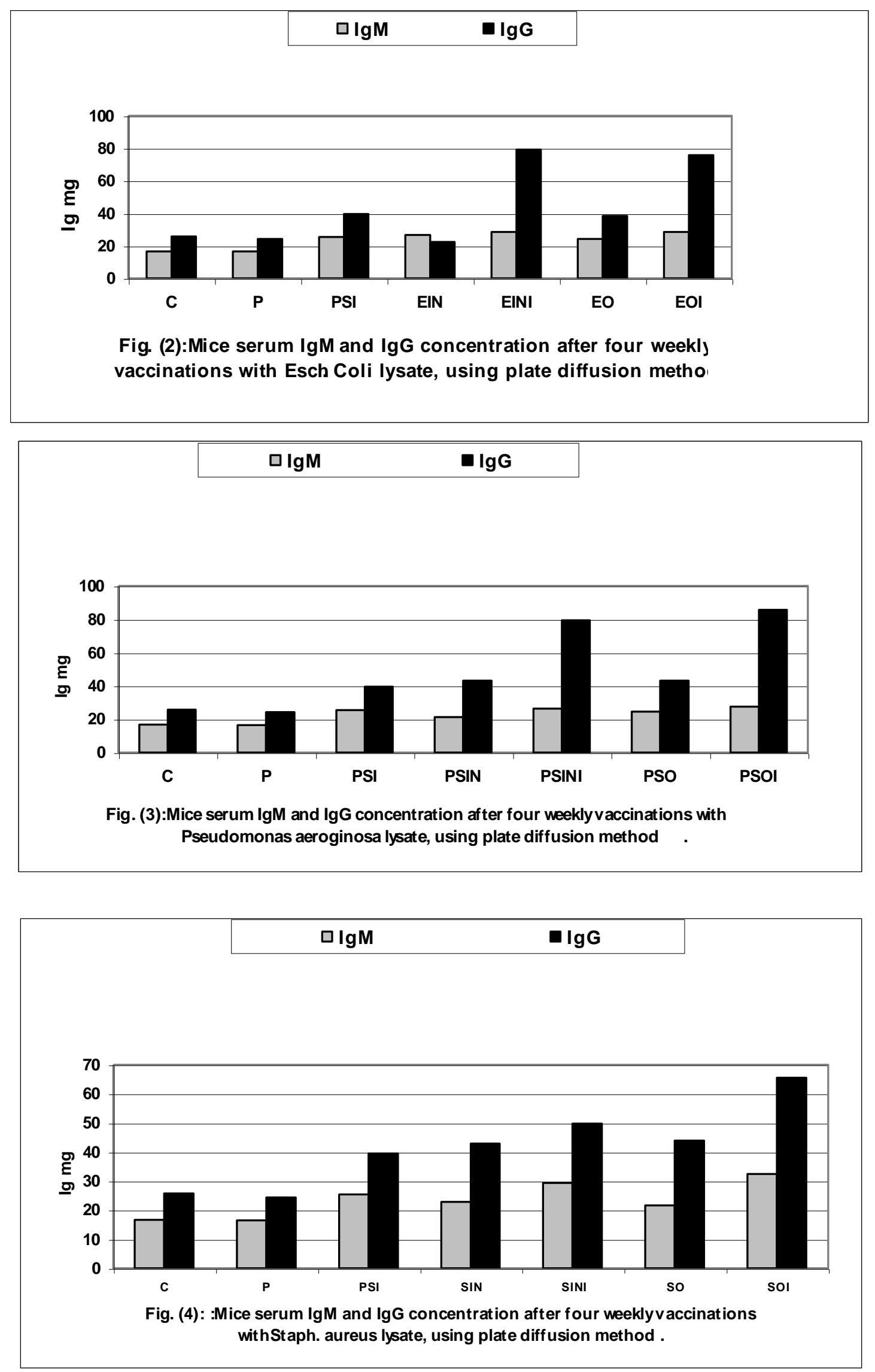


\section{Protective Effect Of Oral And Intranasal.......}

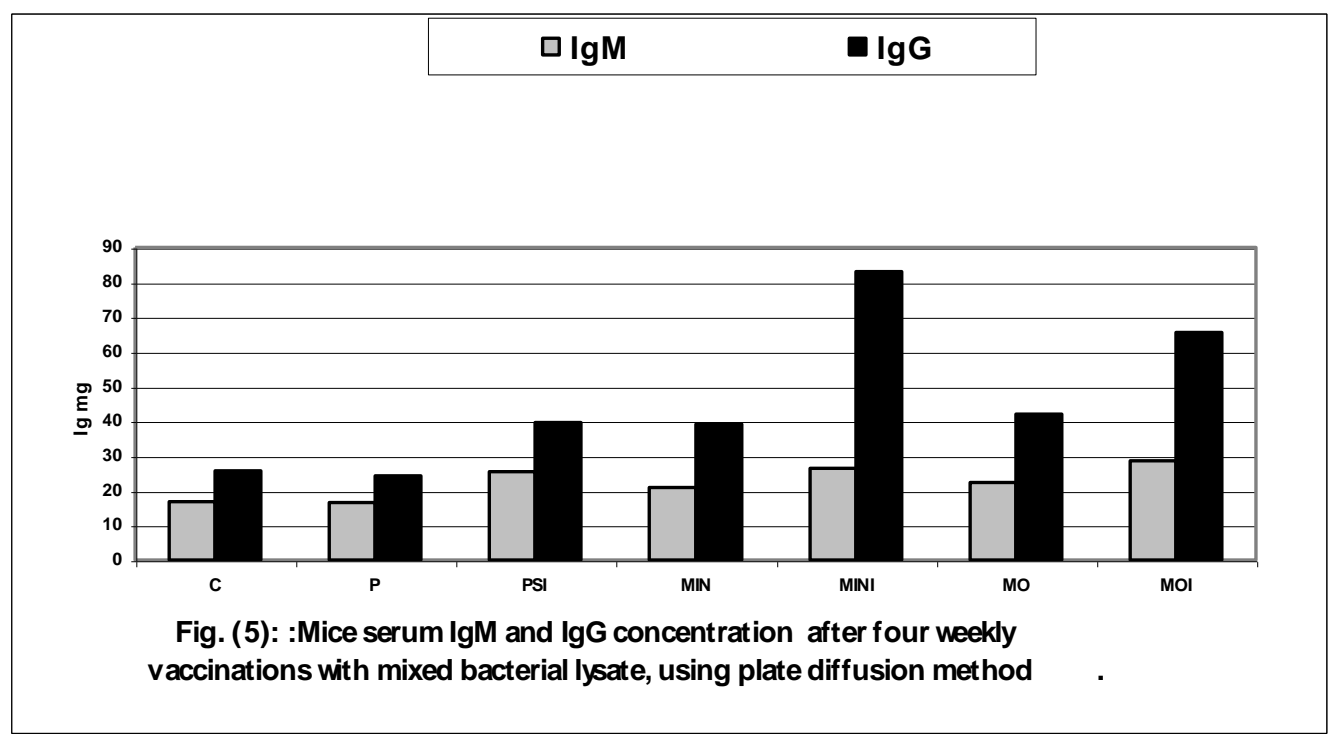

\section{Discussion}

Bacterial vaccines are those composed of live attenuated, killed bacteria or bacterial products. This study has approached the immunoprophylaxis effect of bacterial vaccines using the whole cell bacterial lysates. The use of oral and intranasal bacterial vaccines stimulate the local and central effector sites of the mucosa of intestine and respiratory tract. The microrganisms can elicit an enhanced Ig A response according to the concept of a common mucosal immune system axis (Ruedl et al, 1994).

In the present work, Freund's adjuvant has improved the immunoprotective effect elicited by intranasal and oral bacterial lysates vaccination in intraperitoneally bacterial challenged animals where intraperitoneal peritonitis/ sepsis model have shown enhanced survival rates. Bennett- Guerrero et al (2000) showed that liposomal core LPS- active immunization of mice provided protection against a lethal challenge with Esch. coli 018 LPS. Mader et al (1997) have showed that bacterial cell wall complex and antigenic determinants could stimulate the release of tumour necrosis factor- alpha and prostaglandin E2.
Rutishauser et al (1998) and Grevers et al (2000) suggested that bacterial lysate low molecular weight immunomodulators play a major role in the protection against bacterial infections. Other bacterial components that could play a role as immunoprophylactics were ribosomal extracts (Gawlik and Danek, 1999). Our study illustrated the immunoprotective effect of Esch. coli bacterial lysates, both on oral and intranasal vaccinations. On the contrary, Pseudomonas aeroginosa lysate-vaccinated animal groups showed a suppressed immune response and increased lethality in bacterially challenged groups. This could be explained by the finding of Cotran et al (1999) who mentioned that Pseudomonas bacteria secrete a leucotoxin that kills neutrophils. O'Brien et al (2001) have mentioned that attempts to develop vaccine that could enhance neutrophil phagocytosis by stimulating production of opsonizing antibodies to Staph. aureus have met with limited success because of low immunogenicity of the exopolysaccharide capsule surrounding Staph. aureus. Staphylococcus aureus can also adhere to and penetrate epithelial tissue. They proved that Staph 
aureus lysates emulsified in Freund's incomplete adjuvant markedly stimulated the opsonizing antibodies, that were more effective when Staph. aureus lysate was incorporated in microspheres. Our study showed similar results where the protective effect of Staph. aureus lysate in LD50 bacterially challenged animals was enhanced by Freund's adjuvant. This effect was observed in oral and intranasal vaccinated animals and it was associated with peripheral blood changes and reticuloendothelial system changes, in addition to elevation of serum Ig G and Ig M.

Bonenfant et al (2001) have explained the immunoprotective effect of intranasal immunization. They showed that mucosal adjuvants can significantly enhance the immunogenicities of intranasally administered antigens. Cholera toxin and heat-labile enterotoxin are strong mucosal adjuvants with a variety of antigens. These two adjuvants were tested with Toxoplasma gondii SAG1 protein in intranasal vaccinated mice. Their study showed that gamma interferon and interleukin- 2 (IL-2) production by splenocytes and (IL-2) production by mesenteric lymph nodes cells were observed in vitro after antigen restimulation, underlying Th-1 like response. Effective protection against pathogens required both mucosal and systemic immune responses. Mucosal adjuvants can significantly enhance the immunogenicities of intranasally administered antigens. Our study could prove this immunostimulant effect of mucosal adjuvants. The animal groups treated intranasally or orally with Freund's adjuvant reported higher survival rates against bacterial challenge. Kuenen et al, 1994 have mentioned that the protective effect of bacterial lysates was accompanied by priming for specific Ig $\mathrm{G}$ responsiveness ( probably at the $\mathrm{T}$ cell level ) and a significant Ig A serum antibody levels. Our study have proved that repeated intranasal and oral vaccinations induced strong systemic immunoglobulin $\mathrm{G}$ and immunoglobulin $\mathrm{M}$ ( $\mathrm{Ig} \mathrm{G}$ \& $\mathrm{Ig} \mathrm{M}$ ) response. This response was highly signifycant in bacterially challenged animals. Other studies showed that the stimulated systemic response was associated with stimulated mucosal (IgA) humoral response upon intranasal immunization ( Bonenfant et al, 2001) and oral immuni-zation with Salmonella typhimurium ( Harrison et al, 1997) and Helicobacter pylori lysate ( Kim et al, 1999 ) who mentioned that the presence of antibody-secreting cells in intestinal lamina propria lymphocytes was correlated with Ig A level in gut washing fluids. These levels were highly increased on repeated oral booster immunization with Helicobacter pylori whole-cell lysate. Ciebiada et al (1989) showed that the use of BCG and Corynbacterium pavum vaccines whether oral or intranasal in bacterial challenged and non-bacterial challenged animal groups have shown histological changes and morphological differences in the liver, spleen, thymus and lymph nodes depending on the type of the vaccine used . The preparations were characterized by stimulating effect on the reticuloendothelial system. Our study showed that these reticulendothelial system changes were assocaited with haematological changes in the peripheral blood, peritoneal fluid and the bone marrow lymphocytic percentage. These changes were directy reflected on survival rates in the bacterially challenged animal groups.

This study concludes that bacterial lysates and mixed bacterial lysates have an immunomodulatory / immunostimulatory effect. This effect varies according to the type of the bacterial lysate used. Freund's adjuvent enhances the immunostimulatory effect of intranasal and oral applied bacterial lysates.

\section{Refrences}

1. Ambrosino, D.M. 1996: Bacterial vaccines. In: Therapeutic Immunology . K.F. Austen; S.J. Burakoff and F.S. Rosen (eds.) pp. 419-427. Blackwell Science.

2. Barackman, J.D.; Ott, G. and O'Hagan, D. T. 1999: Intranasal immunization of mice with influenza vaccine in combination with the adjuvant Lt-R72 induces potent mucosal and serum immunity which is stronger than that with raditional intramuscular immunization. Infect. Immun. 67: 4276-4279.

3. Bennet-Guerrero, E.; McIntosh T.J.; Barclay, G.R.; Snyder, D.S.; Gibbs, R.; 
Mythen, M.G and Poxton, I.R.; 2000: Preparation and preclinical evaluation of a novel liposomal complete-core lipopoly saccharide vaccine. Infecct. Immun. 68(11): 6202-6208.

4. Bey, R.; Simonson, R. and Garcon, N.1997: Formulation of vaccines. In: Development and Formation of Veterinary Dosage Forms. G.E. Hardee and J.D. Baggot (eds.). pp. 283-303. Marcel Dekker Inc. New York. Basel. Hong Kong.

5. Bonenfant, C.; Dimier-Boisson, I.; VelgeRoussal, F.; Buzoni Gatel, D.D.; Guidice, G.; Rappuoli,R. and Bout, D. 2001: Intranasal immunization with SAG 1 and nontoxic mutant heat labile enterotoxins protects mice against Toxoplasma gondii. Infect. Immun. 69 (3): 1605-1612.

6. Ciebiada, I.; Bloch, P.; Kulig,A. and Denys, A. 1989: Studies of the effects of BCG and Corynbacterium parvum vaccines in experimental infection of mice with influenza virus. Foot pad test, splenic indicator and histologic changes in the thymus gland, spleen and lysmph nodes. Med. DOSW Microbiol. 41(2): 9299. (Polish, with English abstract).

7. Corthesy-Theulaz, I.E.; Hopkin, S.; Bachmann, D.;Saldinger, P.F.; Porta, N.; Haas, R.; Zheng-Xin, Y.; Meyer, T.; Bouzourene, H.; Blum, A.L. and Kraehen bulh, J.P. 1998: Mice are protected from Helicobacter pylori infection by nasal immunization with attenuated Salmonellatyphimurium pho Pc expressing urease A and B subunits. Infect. Immun. 66: 581- 586.

8. Cotran, R.S.; Kumar, V. and Collins, T. 1999: Infectious diseases. In: Pathologic Basis Of Disease. (eds.). Pp:332- 402. W.B. Saunders Company. A Division of Harcourt Brace\& Company. Philadelphia, London, Toronto, Montreal, Sydney, Tokyo.

9. Fahey, J.L. and Mc Kelvey, E.M. 1965: Quantitative determination of serum; immunoglobulins in antibody-agar plates. J. Immunol. 94:84-90.

10. Gawlik, R. and Danek, K. 1999: Immunomodulation with bacterial vaccines in chronic respiratory diseases. Wiad Lek. 52 (9-10): 470-475. [In Polish with English abstract].

11. Giuliani, M.M.; Del Giudice, G.; Giannelli, V.; Dougan, G.; Douce. G.; Rappuoli, R. and Pizza, M. 1998: Mucosal adjuvanticity and immunogenicity of LTR72, a novel mutant of Escherichia coli heat- labile enterotoxin with partial knockout of ADPribosyltransferase activity J. Exp. Med. 187:1123-1132.

12. Goldstein, A. 1964: In: Biostatestics, and introductory text. Macmillan, Co. New York, PP. 101-106.

13. Grevers, G.; Palacios, O.A.; Rodriquez, B.; Abel, S. and van Aubel, A. 2000: Treatment of recurrent respiratory tract infections with a polyvalent bacterial lysate: results of an open, prospective multinational study. Adv. Ther. 17 (2):103-116.

14. Hamid, M.R. 1989: Toxicological screening; A route for amore scientific toxicology. J. Drug Res. Egypt. 18 (12):211-219.

15. Hanaa, A.M.; 1999: The effect of dexamethasone on the toxin- antitoxin neutralization test. Ain Shams Med. J. 50(1,2 \& 3): 251-263.

16. Harrison, J.A.; Villareal-Ramos, B.; Mastroeni, P.; Demarco de Horma, R. and Hormaeche, C.E. 1997: Correlates of protection induced by live AroSalmonella typhimurium vaccines in the murine typhoid model. Immunology. 90 (4): 618-625.

17. Hugo, W.B. and Russel, A.D. 1993: The manufacture and quality control of immunological products. In:Pharmaceutical Microbiology. (eds). Pp. 332-350. Blackwell Scientific Publications. London. Edinburg. Boston. Melbourne. Paris. Berlin. Vienna.

18. Jackson, R.J.; Fujihashi, K.; Xu-Amano, J.; Hiyono, H.; Elson, C.O. and Mc Ghee, J.R. 1993: Optimizing oral vaccines: induction of systemic and mucosal B-cell and antibody responses to tetanus toxoid by use of cholera toxin as an adjuvant. Infect. Immun. 61: 4272-4279.

19. Kim, S.Y.; Doh, H.J.; Ahn, J.S.; Ha, Y. J.; Jang, M.H.; Chung, S.I. and Park, H.J. 1999: Induction of musocal and systemic immune response by oral immunization with $\mathrm{H}$. Pylori lysates capsulated in poly (Di lactide-coglycolide) microparticles. Vaccine. 17 (6): 607-616.

20. Kiyono, H.; Bienenstock, J.; Mc Ghee, J. R. and Ernst, P.B.1992: The mucosal immune system: features of inductive and effector sites to consider in mucosal immunization and vaccine evelopment. Reg. Immunol.4:54-62.

21. Kuenen, J. D.; Van Dijke, E.E.; Hol, C.; Bootsma, H.J.; Verhoef, J.and Van Dijk, 


\section{Hanaa, A. Mansour \& Maha G. Soliman}

H. 1994: Protective effects of orally administered, klebsiella-containing bacterial lysates in mice. FEMS Immunol. Med. Microbiol. 8 (1).: 69-75.

22. Kurstak, E.; 1994: In: Modern Vaccinology (ed.). Plenum Publishing Corp. New York.

23. Mader, H.J.; Szostak, M.P.; Hensel, A.; Lubitz and Haslberger, A.G. 1997: Endotoxicity does not limit the use of bacterial ghosts as candidate vaccines. Vaccine. 15 (2); 195-202.

24. O'Brien, C.N.; Guidry, A.J.; Douglass, L.W. and Westhoff, D.C. 2000: Immunization with Staphylococcus aureus lysate incorporaints microsphers. J. Dairy Sci. 84(8): 1791-1799.

25. Orr, N.; Robin, G. and Cohen, D. 1993: Immunogenicity and efficacy of oral or intranasal Shigella flexneri and shigella sonnei proteosome-lipopolysaccharide vaccines in animal models. Infect. Immun. 61: 2390-2395.

26. Raghavan,S.; Hjulstrom, M.; Holingren, J. and Svennerholm, A.M. 2002: Protection against experimental Helicobactor pylori infection after immunization with inactivated $\mathrm{H}$. pylori whole-cell vaccines. Infect. Immun. 70 (11): 6383 6388 .
27. Ruah, S.B.; Ruah, C.; Van Aubel, A.; Abel, S. and Elsasser, U.2001 : Efficacy of a polyvalent bacterial lysate in children with recurrent respiratory tract infections. Adv. Ther. 18 (4): 151-162.

28. Ruedlc.; Fruhwirth, M.; Wick, G. and Wolf H. 1994: Immune response in the lengs following oral immunization with bacterial lysates of respiratory pathogens. Clin. Diagn. Lab. Immunol. 1(2): 150-154.

29. Rutishauser, M.; Pitzke, P.; Grevers, G.; Van Aubel, A.; Elsasser, U. and Kammereit, A. 1998: Use of a polyvalent bacterial lysate in patients with recurrent respiratory tract infections: results of a prospective, placebo-controlled, randomized, double - blind study. Adv. Ther. 15 (6):330-341

30. Sadeq, R.A.; El-Kady, L. and Fahmy, K. 1992: Requirements of Opsonophagocytosis of Staphylococci. Egypt. J. Med. Microbiol. 1 (1): 35-38.

31. Sramek, J.; Josifko, M.; Helcl, J.; Holoubkova, E.; Janout, V.; Kozesnik, B. and Macatova , I. 1986: Bacterial lysate (I.R.S.19) applied intransally in the prevention of acute respiratory diseases in children; a randomized double blind study. J.Hyg. Epidemiol Microbiol. Immunol. 30 (4): 377-385. 


\section{التأثير الواقى للأستخدام الفمى والأنفى للمتحلات البكتيرية

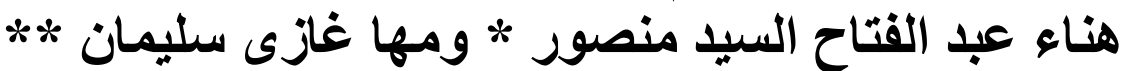

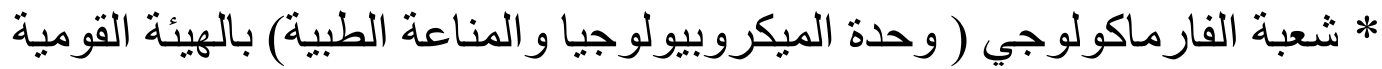

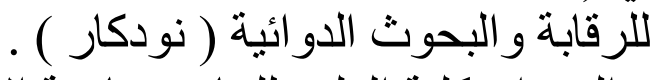

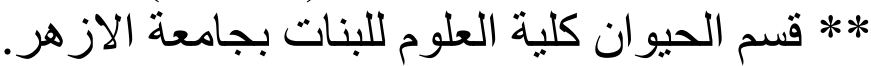

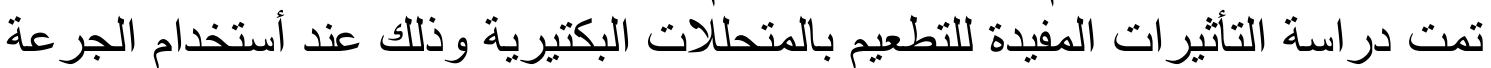

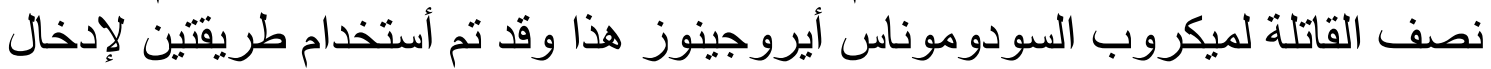

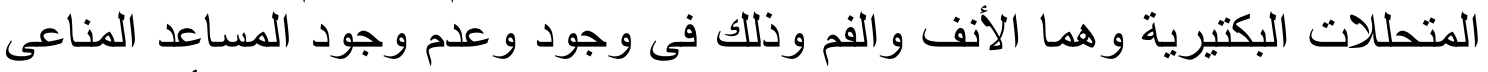

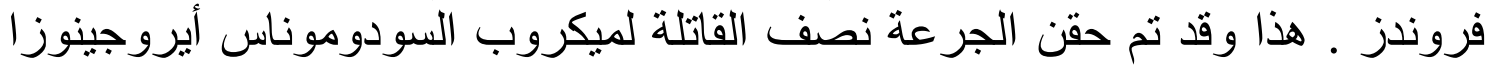

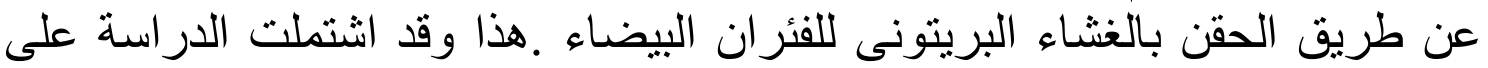

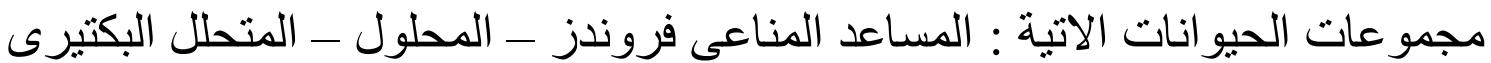

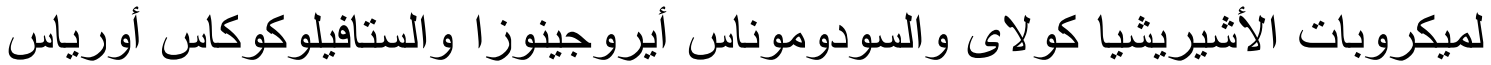

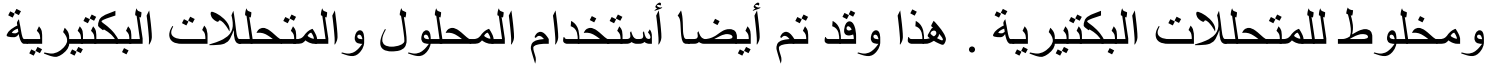

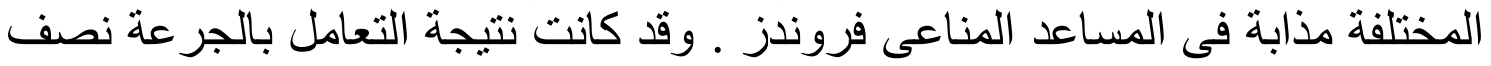

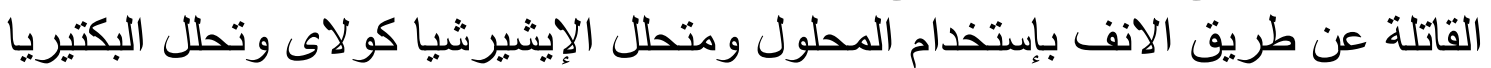

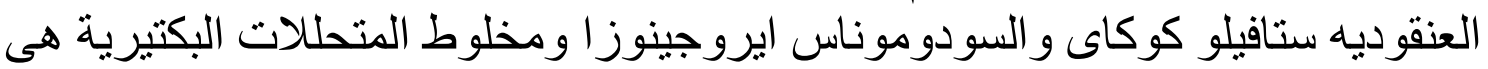
50\% و 37.5 \% و 100\% وصفر \% \% و 12.5 \% \% على التو الى و عند استخدامها مع هـ

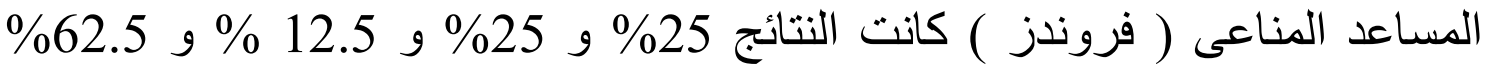
وصفر \% و صفر \% ع على التوالى ـ و عند استخدام نفس التطعيمات عن طريق الفم

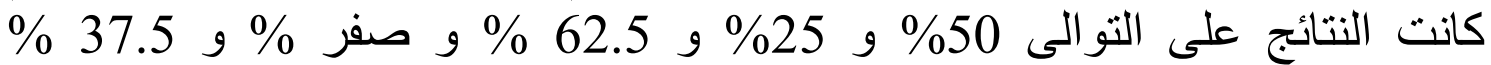

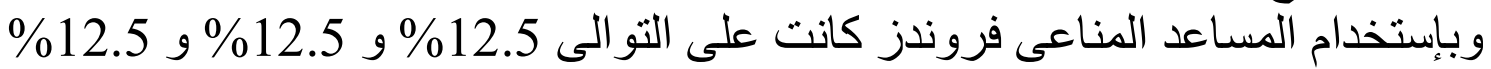

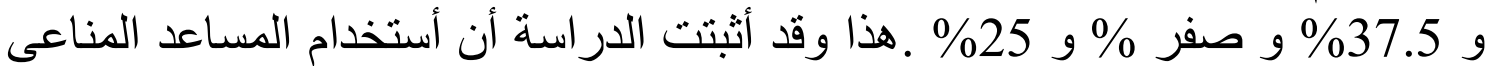

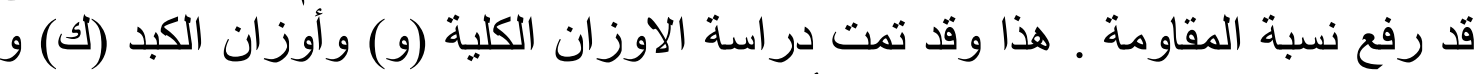

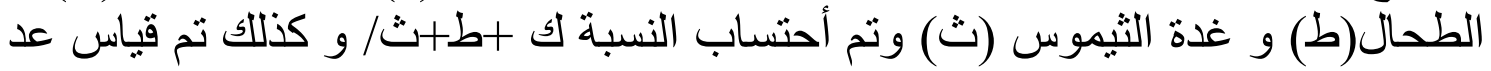

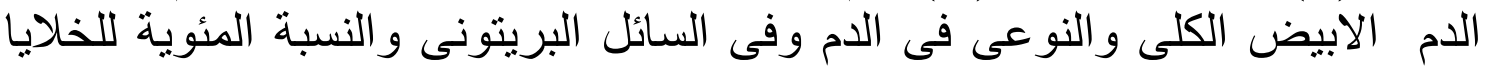

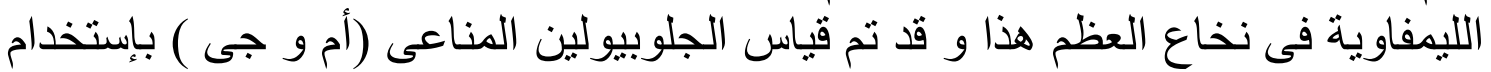

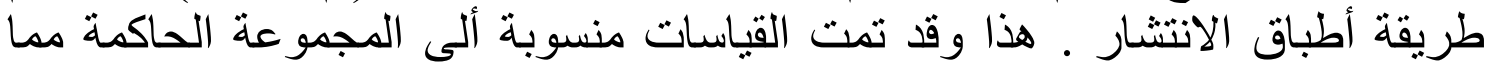

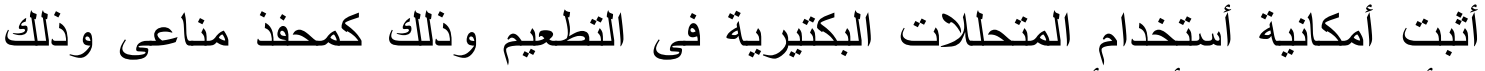

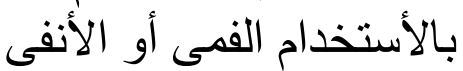

